\title{
Potent SARS-CoV-2 mRNA cap methyltransferase inhibitors by bioisosteric replacement of methionine in SAM co-substrate
}

Olga Bobileva,${ }^{\dagger}$ Raitis Bobrovs,${ }^{\dagger}$ Iveta Kanepe,${ }^{\dagger}$ Liene Patetko,${ }^{\dagger}$ Gints Kalniňš,${ }^{\S}$ Mihails

Šišovs, ${ }^{\S}$ Anna L. Bula,${ }^{\dagger}$ Solveiga Grīnberga,${ }^{\dagger}$ Mārtiņš Boroduškis,,${ }^{\ddagger}$ Anna Ramata-Stunda,,

Nils Rostoks, ${ }^{\ddagger}$ Aigars Jirgensons, ${ }^{\dagger}$ Kaspars Tārs, ${ }^{\S}$ Kristaps Jaudzems ${ }^{\dagger *}$

'Latvian Institute of Organic Synthesis, Aizkraukles 21, Riga LV-1006, Latvia

University of Latvia, Jelgavas 1, Riga LV-1004, Latvia

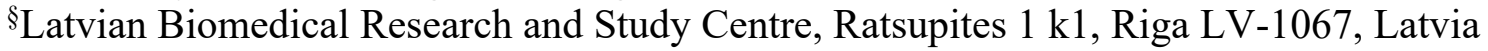

\section{Contents}

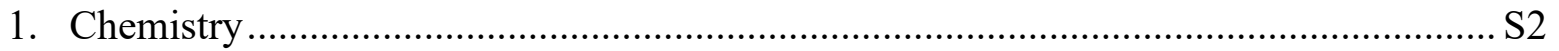

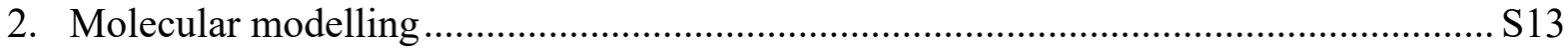

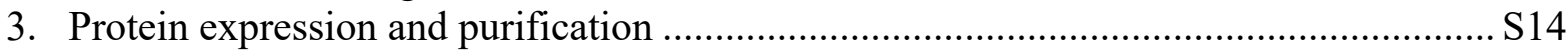

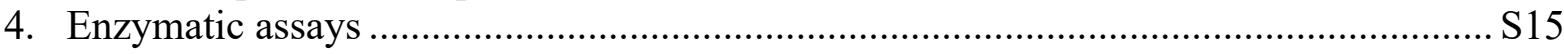

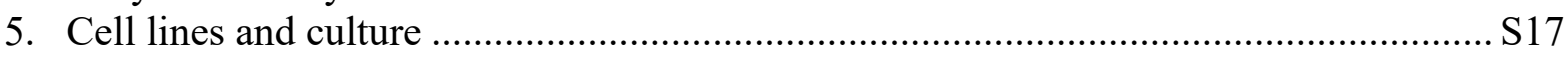

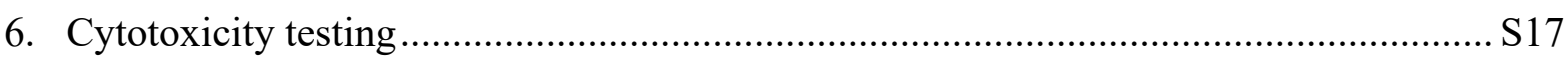

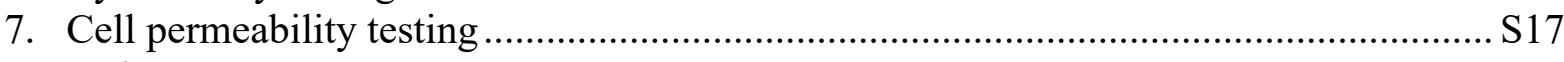

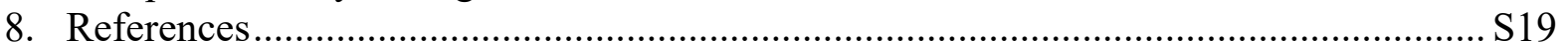




\section{Chemistry}

\subsection{General}

Reagents and dry solvents (DMF, acetonitrile, and methanol) were obtained from commercial sources and used without purification. Dry THF and DCM were prepared on MB-SPS MBraun solvent purifier system. Reaction conditions and yields were not optimized. Normal phase chromatography was performed on Davisil $60 \AA 35-70 \mu \mathrm{m}$ silica and reverse-phase chromatography was performed using KP-C18-HS SNAP Biotage cartridges on a Biotage Isolera One purification system. Reactions were monitored by thin-layer chromatography using Merck $F_{254}$ Alumina Silica Plates using UV visualization or staining. NMR spectra were recorded on 300 or $400 \mathrm{MHz}$ Bruker spectrometer. Chemical shifts are reported in parts per million and referenced to the residual solvent signal. HRMS (ESI+) was obtained on a Waters Synapt G2-Si TOF mass spectrometer. Analytical HPLC data was obtained using Waters Alliance LC systems equipped with 2695 separation module with LiChrospher PR Select 4.0 x $250 \mathrm{~mm}$ or Apollo $5 \mu \mathrm{m} \mathrm{C18} 4.6$ x $150 \mathrm{~mm}$ column and Waters 2489 dual absorbance detector. Gradient $0-100 \%$ over 15 min; solvent A: $5 \%$ acetonitrile in $0.1 \% \mathrm{H}_{3} \mathrm{PO}_{4}$; solvent $\mathrm{B}$ : $95 \%$ acetonitrile in $0.1 \% \mathrm{H}_{3} \mathrm{PO}_{4}$; flow rate: $1 \mathrm{ml} / \mathrm{min}$; column temperature: $40^{\circ} \mathrm{C}$.

\subsection{Synthesis of SAM analogue 1a, 2c}

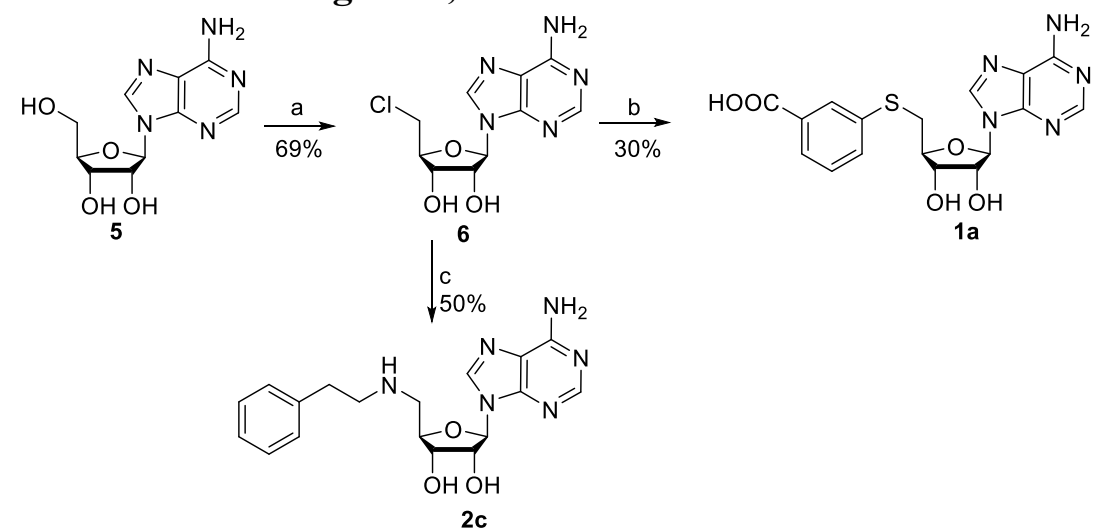

Reagents and conditions: (a) $i \mathrm{SOCl}_{2}$, pyridine, $\mathrm{MeCN}, 0^{\circ} \mathrm{C}$ to rt; $i i \mathrm{NH}_{4} \mathrm{OH}, \mathrm{MeOH}$; (b) 3-mercaptobenzoic acid, $\mathrm{Cs}_{2} \mathrm{CO}_{3}$, DMF, rt; (c) 2-phenylethylamine, DIPEA, $90^{\circ} \mathrm{C}$.

\section{5'-Chloro-5'-deoxyadenosine 6}

To a suspension of adenosine $(1.50 \mathrm{~g}, 5.61 \mathrm{mmol})$ in dry acetonitrile $(6 \mathrm{ml})$ under an argon atmosphere was added thionyl chloride $(1.20 \mathrm{ml}, 16.5 \mathrm{mmol})$ dropwise cooling in the ice bath and keeping the temperature below $4^{\circ} \mathrm{C}$. Pyridine $(900 \mu \mathrm{l}, 11.1 \mathrm{mmol})$ was added keeping temperature below $4^{\circ} \mathrm{C}$ and the mixture was stirred in the ice bath for $3 \mathrm{~h}$, then the mixture was allowed to warm to room temperature and stirred $16 \mathrm{~h}$. The precipitate was dissolved by adding water $(15 \mathrm{ml})$ to the reaction mixture. The solution was neutralized to $\mathrm{pH} 5$ by the slow addition of sodium bicarbonate. The precipitate was collected by vacuum filtration, washed with cold water $(2 \times 5 \mathrm{ml})$, and dried in vacuo to give $1.36 \mathrm{~g} \mathrm{(77 \% )}$ of the sulfinyladenosine intermediate. A suspension containing $1.36 \mathrm{~g}$ of the sulfinyladenosine in $\mathrm{MeOH}(15 \mathrm{ml})$ was treated with 1.5 $\mathrm{ml}$ of ammonium hydroxide. Precipitate was formed upon stirring at room temperature for $1 \mathrm{~h}$, the precipitate was filtered, washed with cold $\mathrm{MeOH} /$ ammonium hydroxide solution $(10: 1,2 \times 5$ $\mathrm{ml})$, and dried under vacuum to give $1.11 \mathrm{~g}(69 \%)$ of the product 6 as a white solid. ${ }^{1} \mathrm{H}$ NMR (300 MHz, DMSO-d6) $\delta 8.34(\mathrm{~s}, 1 \mathrm{H}), 8.15(\mathrm{~s}, 1 \mathrm{H}), 7.29$ (br s, 2H), $5.93(\mathrm{~d}, J=5.6 \mathrm{~Hz}, 1 \mathrm{H})$, $5.60(\mathrm{br} \mathrm{d}, 1 \mathrm{H}), 5.46(\mathrm{br} \mathrm{d}, 1 \mathrm{H}), 4.75(\mathrm{q}, J=5.2 \mathrm{~Hz}, 1 \mathrm{H}), 4.22(\mathrm{~d}, J=4.5 \mathrm{~Hz}, 1 \mathrm{H}), 4.26-4.18$ $(\mathrm{m}, 1 \mathrm{H}), 4.14-4.05(\mathrm{~m}, 1 \mathrm{fH}), 3.94(\mathrm{dd}, J=11.6,5.0 \mathrm{~Hz}, 1 \mathrm{H}), 3.84(\mathrm{dd}, J=11.6,6.3 \mathrm{~Hz}, 1 \mathrm{H})$. Data are consistent with literature values. ${ }^{1}$ 
3-((((2S,3S,4R,5R)-5-(6-Amino-9H-purin-9-yl)-3,4-dihydroxytetrahydrofuran-2yl)methyl)thio)benzoic acid 1a

A suspension of 5'-chloro-5'-deoxyadenosine 6 (70 $\mathrm{mg}, 0.25 \mathrm{mmol}), 3$-mercaptobenzoic acid (42 $\mathrm{mg}, 0.27 \mathrm{mmol})$ and cesium carbonate $(0.18 \mathrm{~g}, 0.55 \mathrm{mmol})$ in dry DMF $(1.2 \mathrm{ml})$ were stirred in a closed vial under argon atmosphere for $5 \mathrm{~h}$. The solvent was evaporated under reduced pressure. The residue was treated with water $(5 \mathrm{ml})$, cooled in the ice bath and neutralized to $\mathrm{pH} 5$ with $1 \mathrm{M} \mathrm{HCl}$. The precipitate was filtered off, washed with water $(2 \times 2$ $\mathrm{ml}$ ), dried in vacuo. The residue was chromatographed on $\mathrm{C} 18$ silica on Biotage, eluent acetonitrile in $0.1 \% \mathrm{HCOOH}$, gradient $5-80 \%$, and then freeze-dried to give $30 \mathrm{mg}(30 \%)$ of the product 1a as a white solid. HPLC purity 97\%. ${ }^{1} \mathrm{H}$ NMR (400 MHz, DMSO-d6) $\delta 8.33(\mathrm{~s}$, $1 \mathrm{H}), 8.15(\mathrm{~s}, 1 \mathrm{H}), 7.85(\mathrm{t}, J=1.6 \mathrm{~Hz}, 1 \mathrm{H}), 7.73(\mathrm{dt}, J=7.8,1.3 \mathrm{~Hz}, 1 \mathrm{H}), 7.59$ (ddd, $J=7.8$, 1.9, 1.1 Hz, 1H), $7.41(\mathrm{t}, J=7.8 \mathrm{~Hz}, 1 \mathrm{H}), 7.29(\mathrm{~s}, 2 \mathrm{H}), 5.89$ (d, $J=5.9 \mathrm{~Hz}, 1 \mathrm{H}), 5.53(\mathrm{~d}, J=$ $6.1 \mathrm{~Hz}, 1 \mathrm{H}), 5.41(\mathrm{~d}, J=4.9 \mathrm{~Hz}, 1 \mathrm{H}), 4.82(\mathrm{q}, J=5.6 \mathrm{~Hz}, 1 \mathrm{H}), 4.23-4.18(\mathrm{~m}, 1 \mathrm{H}), 4.01$ (ddd, $J=7.0,5.9,3.3 \mathrm{~Hz}, 1 \mathrm{H}), 3.53-3.30(\mathrm{~m}, 2 \mathrm{H}$, overlapped with water). The signal of carboxylic acid group exchangeable proton was not observed by ${ }^{1} \mathrm{H}$ NMR due to fast exchange with residual water protons. ${ }^{13} \mathrm{C}$ NMR $(100 \mathrm{MHz}$, DMSO-d6) $\delta 166.9,156.1,152.7,149.5,140.0$, 136.8, 132.3, 131.7, 129.4, 128.4, 126.7, 119.3, 87.6, 82.8, 72.8, 72.6, 35.1. HRMS (ESI/TOFQ) $\mathrm{m} / \mathrm{z}:[\mathrm{M}+\mathrm{H}]^{+}$calcd for C17H18N5O5S, 404.1029; found, 404.1036.

$(2 R, 3 R, 4 S, 5 R)-2-(6-A m i n o-9 H-p u r i n-9-y l)-5-(($ phenethylamino)methyl)tetrahydrofuran-3,4diol 2c

A mixture of $5^{\prime}$-chloro-5'-deoxyadenosine $6(0.15 \mathrm{~g}, 0.53 \mathrm{mmol}), 2$-phenylethylamine $(0.26$ $\mu \mathrm{l}, 2.1 \mathrm{mmol})$ and DIPEA $(90 \mu \mathrm{l}, 0.52 \mathrm{mmol})$ was stirred under argon atmosphere in a closed vial at $90^{\circ} \mathrm{C}$ for $17 \mathrm{~h}$. The reaction mixture was concentrated under reduced pressure, dissolved in DCM (5 ml) upon gentle heating, then cooled to room temperature. A precipitate was filtered off and washed with DCM. The precipitate was chromatographed on C18 silica on Biotage, eluent acetonitrile in $0.1 \% \mathrm{HCOOH}$, gradient $0-50 \%$ to give $0.11 \mathrm{~g}(50 \%)$ of the product $2 \mathrm{c}$ as a white foam, which contains 1 equivalent of $\mathrm{HCOOH}$. HPLC purity $97 \%$. ${ }^{1} \mathrm{H}$ NMR $(300 \mathrm{MHz}$, $\left.\mathrm{D}_{2} \mathrm{O}\right) \delta 8.46(\mathrm{~s}, 1 \mathrm{H}, \underline{\mathrm{HCOOH}}), 8.18(\mathrm{~s}, 1 \mathrm{H}), 7.99(\mathrm{~s}, 1 \mathrm{H}), 7.15-6.98(\mathrm{~m}, 5 \mathrm{H}), 7.06-6.96(\mathrm{~m}$, $3 \mathrm{H}), 5.97(\mathrm{~d}, J=6.0 \mathrm{~Hz}, 1 \mathrm{H}), 4.87-4.79(\mathrm{~m}, 1 \mathrm{H}$ overlapped with water), $4.51-4.43(\mathrm{~m}, 1 \mathrm{H})$, $4.40(\mathrm{dd}, J=4.9,3.5 \mathrm{~Hz}, 1 \mathrm{H}), 3.49-3.41(\mathrm{~m}, 2 \mathrm{H}), 3.41-3.25(\mathrm{~m}, 2 \mathrm{H}), 3.07-2.94(\mathrm{~m}, 1 \mathrm{H})$, $2.94-2.82(\mathrm{~m}, 1 \mathrm{H})$. The signals of exchangeable protons from two hydroxyl groups, one secondary amine and one primary amine groups were not observed by ${ }^{1} \mathrm{H}$ NMR. ${ }^{13} \mathrm{C}$ NMR (100 $\left.\mathrm{MHz}, \mathrm{D}_{2} \mathrm{O}\right) \delta 170.6(\mathrm{H} \underline{\mathrm{COOH}}), 155.2,152.2,147.9,141.0,135.3,128.5,128.5,127.0,119.4$, 89.3, 78.9, 72.6, 71.6, 47.5, 47.3, 31.2. HRMS (ESI/TOF-Q) $\mathrm{m} / \mathrm{z}:[\mathrm{M}+\mathrm{H}]^{+}$calcd for C18H23N6O3, 371.1826; found, 371.1844.

\subsection{Synthesis of SAM analogue $1 \mathrm{~b}$}

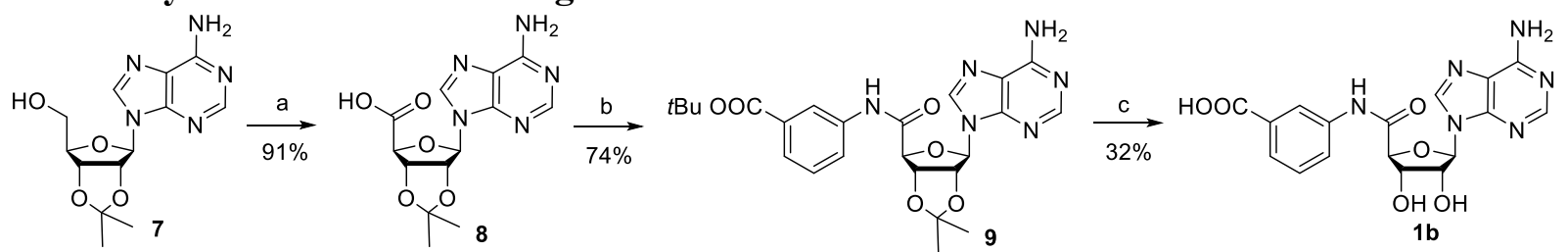

Reagents and conditions: (a) PIDA, TEMPO, MeCN, rt; (b) tert-butyl 3-aminobenzoate, HATU, DIPEA, MeCN, rt; (c) $\mathrm{HCOOH}$, water, rt.

(3aS,4S,6R,6aR)-6-(6-Amino-9H-purin-9-yl)-2,2-dimethyltetrahydrofuro[3,4-d][1,3]dioxole4-carboxylic acid 8

To a suspension of 2',3'-O-isopropylidenadenosine $7(1.00 \mathrm{~g}, 3.25 \mathrm{mmol})$ in acetonitrile and water mixture (1:1, $6 \mathrm{ml})$ was added (diacetoxyiodo)benzene $(2.30 \mathrm{~g}, 7.15 \mathrm{mmol})$ and TEMPO 
(101 mg, $0.646 \mathrm{mmol})$ under argon atmosphere at room temperature. The reaction mixture was stirred at room temperature for $3 \mathrm{~h}$. The mixture was filtered, the residue was washed with water $(3 \mathrm{ml}), \mathrm{Et}_{2} \mathrm{O}(5 \mathrm{ml})$, acetone $(5 \mathrm{ml}), \mathrm{Et}_{2} \mathrm{O}(8 \mathrm{ml})$, then dried in vacuo to give $0.95 \mathrm{~g}(91 \%)$ of the product 8 as a white solid. ${ }^{1} \mathrm{H}$ NMR $\left(300 \mathrm{MHz}, \mathrm{DMSO}-d_{6}\right) \delta 12.79(\mathrm{br} \mathrm{s}, 1 \mathrm{H}), 8.24(\mathrm{~s}$, $1 \mathrm{H}), 8.08(\mathrm{~s}, 1 \mathrm{H}), 7.27(\mathrm{br} \mathrm{s}, 2 \mathrm{H}), 6.33(\mathrm{~s}, 1 \mathrm{H}), 5.54(\mathrm{dd}, J=6.0,1.9 \mathrm{~Hz}, 1 \mathrm{H}), 5.47(\mathrm{~d}, J=6.0$ $\mathrm{Hz}, 1 \mathrm{H}), 4.68(\mathrm{~d}, J=1.9 \mathrm{~Hz}, 1 \mathrm{H}), 1.52(\mathrm{~s}, 2 \mathrm{H}), 1.35(\mathrm{~s}, 2 \mathrm{H})$. Data are consistent with literature values. $^{2}$

tert-Butyl 3-((3aS,4S,6R,6aR)-6-(6-amino-9H-purin-9-yl)-2,2-dimethyltetrahydrofuro[3,4d] [1,3]dioxole-4-carboxamido)benzoate 9

To a suspension of carboxylic acid $8(0.12 \mathrm{~g}, 0.37 \mathrm{mmol})$, HATU $(0.16 \mathrm{~g}, 0.41 \mathrm{mmol})$ and tertbutyl 3-aminobenzoate $(79 \mathrm{mg}, 0.41 \mathrm{mmol})$ in acetonitrile $(5 \mathrm{ml})$ under argon atmosphere was added DIPEA $(84 \mu \mathrm{l}, 0.49 \mathrm{mmol})$. The reaction mixture was stirred at room temperature for 2 $\mathrm{h}$. The reaction mixture was concentrated and the residue was chromatographed on silica gel on Biotage, eluent EtOAc:EtOH 3:1 in petroleum ether $20-80 \%$ to give $0.14 \mathrm{~g}(74 \%)$ of the product 9 as a white solid. ${ }^{1} \mathrm{H}$ NMR $\left(400 \mathrm{MHz}, \mathrm{CDCl}_{3}\right) \delta 8.97(\mathrm{~s}, 1 \mathrm{H}), 8.29(\mathrm{~s}, 1 \mathrm{H}), 7.91(\mathrm{~s}$, $1 \mathrm{H}), 7.77$ (ddd, $J=8.0,2.1,1.1 \mathrm{~Hz}, 1 \mathrm{H}), 7.71(\mathrm{ddd}, J=7.8,1.5,1.1 \mathrm{~Hz}, 1 \mathrm{H}), 7.67(\mathrm{t}, J=1.8$ $\mathrm{Hz}, 1 \mathrm{H}), 7.32(\mathrm{t}, J=7.9 \mathrm{~Hz}, 1 \mathrm{H}), 6.09(\mathrm{~d}, J=3.2 \mathrm{~Hz}, 1 \mathrm{H}), 5.74(\mathrm{br} \mathrm{s}, 2 \mathrm{H}), 5.43(\mathrm{dd}, J=6.2$, $2.0 \mathrm{~Hz}, 1 \mathrm{H}), 5.38(\mathrm{dd}, J=6.2,3.2 \mathrm{~Hz}, 1 \mathrm{H}), 4.85(\mathrm{~d}, J=2.0 \mathrm{~Hz}, 1 \mathrm{H}), 1.66(\mathrm{~s}, 3 \mathrm{H}), 1.59(\mathrm{~s}, 9 \mathrm{H})$, $1.40(\mathrm{~s}, 3 \mathrm{H}) .{ }^{13} \mathrm{C}$ NMR $\left(100 \mathrm{MHz}, \mathrm{CDCl}_{3}\right) \delta 167.2,165.3,155.9,153.5,149.1,140.1,137.1$, $132.8,129.1,125.7,124.1,120.7,120.6,115.0,92.5,85.8,83.8,82.5,81.5,28.3,27.3,25.3$. HRMS (ESI/TOF-Q) m/z: [M + H] $]^{+}$calcd for C24H29N6O6, 497.2143; found, 497.2150.

3-((2S,3S,4R,5R)-5-(6-Amino-9H-purin-9-yl)-3,4-dihydroxytetrahydrofuran-2carboxamido)benzoic acid $\mathbf{1 b}$

Acetonide 9 was dissolved in ice-cold $\mathrm{HCOOH}$ solution in water $(50 \%, 1 \mathrm{ml})$. The reaction mixture was stirred at $50^{\circ} \mathrm{C}$ for 2 days. The solvent was evaporated, then the residue was coevaporated with $\mathrm{EtOH}$ to remove $\mathrm{HCOOH}$. The residue was chromatographed on $\mathrm{C} 18$ silica on Biotage, eluent acetonitrile in $0.1 \% \mathrm{HCOOH}$, gradient $5-50 \%$, fractions containing the product formed gel. After concentration, the residue was washed with $\mathrm{MeOH}$, then with EtOAc and dried to give $35 \mathrm{mg}(32 \%)$ of the product $\mathbf{1 b}$ as a white solid. HPLC purity $97 \%$. ${ }^{1} \mathrm{H}$ NMR $\left(400 \mathrm{MHz}, \mathrm{DMSO}-d_{6}\right) \delta 10.62(\mathrm{~s}, 1 \mathrm{H}), 8.54(\mathrm{~s}, 1 \mathrm{H}), 8.26(\mathrm{t}, J=1.9 \mathrm{~Hz}, 1 \mathrm{H}), 8.24(\mathrm{~s}, 1 \mathrm{H}), 7.89$ (ddd, $J=8.1,2.3,1.1 \mathrm{~Hz}, 1 \mathrm{H}), 7.78$ (ddd, $J=7.7,1.5,1.1 \mathrm{~Hz}, 1 \mathrm{H}), 7.75$ (br s, 2H), 7.50 (t, $J=$ $7.9 \mathrm{~Hz}, 1 \mathrm{H}), 6.07$ (d, $J=7.0 \mathrm{~Hz}, 1 \mathrm{H}), 5.75$ (br s, 2H), 4.68 (dd, $J=7.0,4.6 \mathrm{~Hz}, 1 \mathrm{H}), 4.56$ (d, $J$ $=2.1 \mathrm{~Hz}, 1 \mathrm{H}), 4.35(\mathrm{dd}, J=4.6,2.1 \mathrm{~Hz}, 1 \mathrm{H})$. The signal of carboxylic acid group exchangeable proton was not observed by ${ }^{1} \mathrm{H}$ NMR due to fast exchange with residual water protons. ${ }^{13} \mathrm{C}$ NMR $\left(100 \mathrm{MHz}, \mathrm{DMSO}-d_{6}\right) \delta 168.6,167.1,154.9,150.9,149.0,140.9,138.3,131.4,129.2$, 125.0, 124.4, 121.0, 119.4, 88.0, 84.5, 73.3, 72.8. HRMS (ESI/TOF-Q) m/z: $[\mathrm{M}+\mathrm{H}]^{+}$calcd for $\mathrm{C} 17 \mathrm{H} 17 \mathrm{~N} 6 \mathrm{O} 6,401.1204$; found, 401.1216. 


\subsection{Synthesis of $S A M$ analogues $2 a, 2 b, 3 a$ and $3 b$}

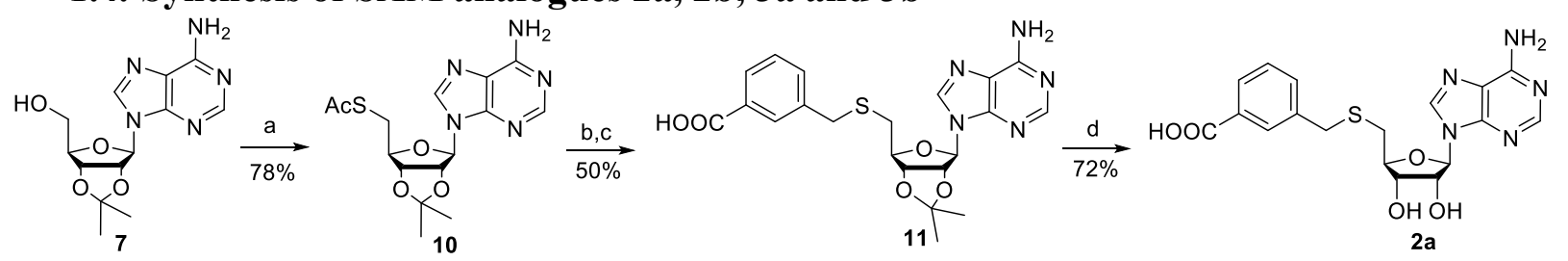

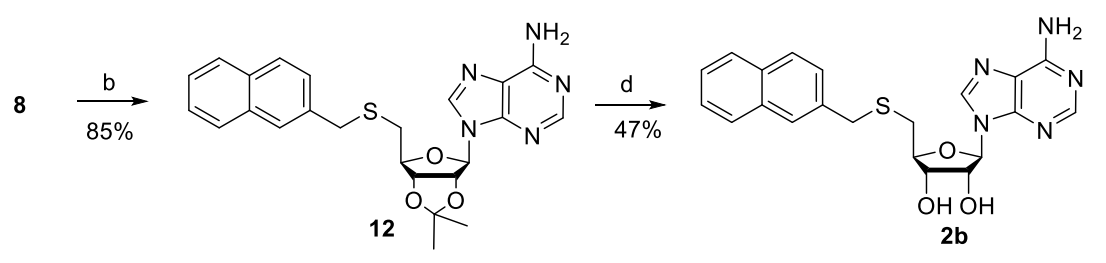<smiles>C#CCCSCC12OC(C)(C)OC1(n1cnc3c(N)ncnc31)O2</smiles>

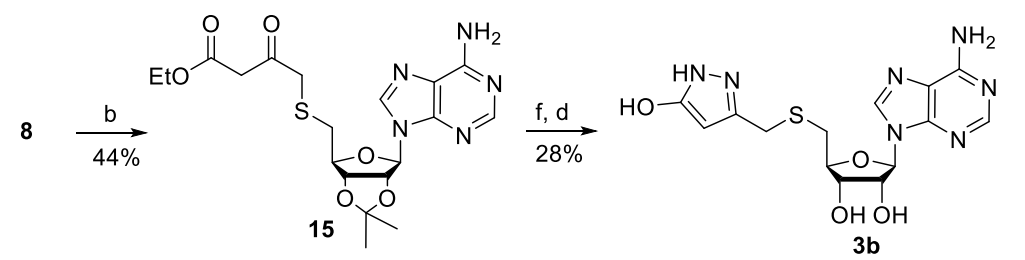

Reagents and conditions: (a) DIAD, $\mathrm{PPh}_{3}, \mathrm{AcSH}, \mathrm{THF}, 0^{\circ} \mathrm{C}$; (b) appropriate $\mathrm{RHal}, \mathrm{NaOMe}, \mathrm{MeOH},-30^{\circ} \mathrm{C}$ to rt; (c) $\mathrm{LiOH}, \mathrm{THF}$, water, rt; (d) $\mathrm{HCOOH}$, water, rt or $50^{\circ} \mathrm{C}$; (e) $\mathrm{TMSN}_{3}, \mathrm{CuI}, \mathrm{DMF}, \mathrm{MeOH}, 100^{\circ} \mathrm{C}$; (f) $\mathrm{NH}_{2} \mathrm{NH}_{2} \cdot \mathrm{H}_{2} \mathrm{O}$, abs. EtOH, rt.

5'-Acetylthio-5'-deoxy-2',3'-O-isopropylideneadenosine $\mathbf{1 0}$

Diisopropyl azodicarboxylate $(0.60 \mathrm{ml}, 3.0 \mathrm{mmol})$ was added dropwise over $5 \mathrm{~min}$ to an icecold solution of triphenylphosphine $(0.80 \mathrm{~g}, 3.0 \mathrm{mmol})$ in dry THF $(5 \mathrm{ml})$. After stirring for 30 min in the ice bath a thick suspension formed, $2^{\prime}, 3^{\prime}$ - $O$-isopropylideneadenosine $7(0.47 \mathrm{~g}, 1.5$ mmol) was added, and the stirring was continued for $10 \mathrm{~min}$ at $0^{\circ} \mathrm{C}$. A solution of thioacetic acid $(0.22 \mathrm{ml}, 3.1 \mathrm{mmol})$ in dry THF $(1 \mathrm{ml})$ was added dropwise to the resulting yellow suspension and stirring was continued for another $1 \mathrm{~h}$ at $0^{\circ} \mathrm{C}$, then allowed to warm to room temperature. The solvent was removed under reduced pressure. The residue was purified by chromatography on silica gel on Biotage, eluent EtOAc:EtOH 3:1 in petroleum ether, gradient $20-80 \%$ to give $0.44 \mathrm{~g}(78 \%)$ of the product 10 as a white solid. ${ }^{1} \mathrm{H}$ NMR $\left(300 \mathrm{MHz}, \mathrm{CDCl}_{3}\right)$ $\delta 8.36(\mathrm{~s}, 1 \mathrm{H}), 7.90(\mathrm{~s}, 1 \mathrm{H}), 6.06(\mathrm{~d}, J=2.1 \mathrm{~Hz}, 1 \mathrm{H}), 5.72(\mathrm{br} \mathrm{s}, 2 \mathrm{H}), 5.51(\mathrm{dd}, J=6.4,2.1 \mathrm{~Hz}$, $1 \mathrm{H}), 4.97(\mathrm{dd}, J=6.4,3.1 \mathrm{~Hz}, 1 \mathrm{H}), 4.34(\mathrm{td}, J=6.9,3.1 \mathrm{~Hz}, 1 \mathrm{H}), 3.29$ (dd, $J=13.8,7.2 \mathrm{~Hz}$, $1 \mathrm{H}), 3.18(\mathrm{dd}, J=13.8,6.6 \mathrm{~Hz}, 1 \mathrm{H}), 2.34(\mathrm{~s}, 3 \mathrm{H}), 1.60(\mathrm{~s}, 3 \mathrm{H}), 1.39(\mathrm{~s}, 3 \mathrm{H})$. Data are consistent with literature values. ${ }^{3}$

3-(((((3aS,4S,6R,6aR)-6-(6-Amino-9H-purin-9-yl)-2,2-dimethyltetrahydrofuro[3,4d][1,3]dioxol-4-yl)methyl)thio)methyl)benzoic acid 11

To a solution of 5'-acetylthio-5'-deoxy-2',3'-O-isopropylideneadenosine 9 (0.11 g, $0.30 \mathrm{mmol})$ and methyl 3-(bromomethyl)benzoate $(76 \mathrm{mg}, 0.33 \mathrm{mmol})$ in dry $\mathrm{MeOH}(1.5 \mathrm{ml})$ sodium methoxide solution in $\mathrm{MeOH}(5.4 \mathrm{M}, 0.12 \mathrm{ml}, 0.65 \mathrm{mmol})$ was added dropwise under argon atmosphere cooling reaction mixture in the dry ice-acetone bath (bath temperature $-30^{\circ} \mathrm{C}$ ). The reaction mixture was stirred at $-30^{\circ} \mathrm{C}$ for $1 \mathrm{~h}$, then allowed to warm to room temperature and stirred for $3 \mathrm{~h}$. The solvent was evaporated under reduced pressure. The residue was diluted with EtOAc $(20 \mathrm{ml})$, washed with saturated $\mathrm{NH}_{4} \mathrm{Cl}$ solution, water, dried over anhydrous 
$\mathrm{Na}_{2} \mathrm{SO}_{4}$ and concentrated. The residue was purified by chromatography on silica gel on Biotage, eluent EtOAc:EtOH 3:1 in petroleum ether, gradient $20-60 \%$ to give $90 \mathrm{mg}$ of the product with impurities, which was used in the next step without additional purification. This residue was vigorously stirred with $\mathrm{LiOH}(14 \mathrm{mg}, 0.58 \mathrm{mmol})$ in THF $(2 \mathrm{ml})$ and water $(1 \mathrm{ml})$ mixture at room temperature for $22 \mathrm{~h}$. The reaction mixture was concentrated, diluted with water $(3 \mathrm{ml})$ and acidified with $1 \mathrm{~N} \mathrm{HCl}$ to $\mathrm{pH} 3$, white precipitate was extracted with EtOAc (2x15 ml), washed with brine, dried over anhydrous $\mathrm{Na}_{2} \mathrm{SO}_{4}$ and evaporated. The residue was washed with small volume of $\mathrm{MeOH}$ to give $70 \mathrm{mg}$ (50\% in 2 steps) of the product 11 as white solid. ${ }^{1} \mathrm{H}$ NMR $\left(400 \mathrm{MHz}\right.$, Methanol- $\left.d_{4}\right) \delta 8.24(\mathrm{~s}, 1 \mathrm{H}), 8.15(\mathrm{~s}, 1 \mathrm{H}), 7.92(\mathrm{t}, J=1.5 \mathrm{~Hz}, 1 \mathrm{H})$, $7.83(\mathrm{dt}, J=7.7,1.4 \mathrm{~Hz}, 1 \mathrm{H}), 7.37(\mathrm{dt}, J=7.7,1.6 \mathrm{~Hz}, 1 \mathrm{H}), 7.29(\mathrm{t}, J=7.7 \mathrm{~Hz}, 1 \mathrm{H}), 6.12(\mathrm{~d}, J$ $=2.4 \mathrm{~Hz}, 1 \mathrm{H}), 5.42(\mathrm{dd}, J=6.4,2.4 \mathrm{~Hz}, 1 \mathrm{H}), 4.94(\mathrm{dd}, J=6.4,3.2 \mathrm{~Hz}, 1 \mathrm{H}), 4.27(\mathrm{td}, J=6.7$, $3.2 \mathrm{~Hz}, 1 \mathrm{H}), 3.73(\mathrm{~s}, 2 \mathrm{H}), 2.73(\mathrm{dd}, J=13.8,6.8 \mathrm{~Hz}, 1 \mathrm{H}), 2.66(\mathrm{dd}, J=13.8,6.6 \mathrm{~Hz}, 1 \mathrm{H}), 1.54$ $(\mathrm{s}, 3 \mathrm{H}), 1.33(\mathrm{~s}, 3 \mathrm{H}) .{ }^{13} \mathrm{C}$ NMR $\left(100 \mathrm{MHz}\right.$, Methanol- $\left.d_{4}\right) \delta 169.6,156.7,152.9,150.0,142.2$, $140.3,134.5,132.2,131.1,129.5,129.4,120.6,115.5,91.6,88.2,85.2,85.1,36.8,34.5,27.4$, 25.5. HRMS (ESI/TOF-Q) $\mathrm{m} / \mathrm{z}:[\mathrm{M}+\mathrm{H}]^{+}$calcd for $\mathrm{C} 21 \mathrm{H} 24 \mathrm{~N} 5 \mathrm{O} 5 \mathrm{~S}, 458.1493$; found, 458.1500 .

3-(((((2S,3S,4R,5R)-5-(6-Amino-9H-purin-9-yl)-3,4-dihydroxytetrahydrofuran-2yl)methyl)thio)methyl)benzoic acid 2a

Acetonide 11 (70 mg, $0.15 \mathrm{mmol})$ was dissolved in ice-cold $\mathrm{HCOOH}$ solution in water $(50 \%$, $1 \mathrm{ml}$ ). The reaction mixture was stirred at $50^{\circ} \mathrm{C}$ for $20 \mathrm{~h}$. The solvent was evaporated, then the residue was co-evaporated with $\mathrm{EtOH}$ to remove $\mathrm{HCOOH}$. The residue was washed with small amount of hot $\mathrm{MeOH}$, then with acetonitrile, dried in vacuo to give $46 \mathrm{mg}(72 \%)$ of the product 2a as white solid. HPLC purity 91\%. ${ }^{1} \mathrm{H}$ NMR (400 MHz, DMSO- $\left.d_{6}\right) \delta 12.95$ (br zs, $\left.1 \mathrm{H}\right), 8.33$ $(\mathrm{s}, 1 \mathrm{H}), 8.12(\mathrm{~s}, 1 \mathrm{H}), 7.89(\mathrm{t}, J=1.5 \mathrm{~Hz}, 1 \mathrm{H}), 7.80(\mathrm{dt}, J=7.7,1.5 \mathrm{~Hz}, 1 \mathrm{H}), 7.46(\mathrm{dt}, J=7.7$, $1.5 \mathrm{~Hz}, 1 \mathrm{H}), 7.39(\mathrm{t}, J=7.7 \mathrm{~Hz}, 1 \mathrm{H}), 7.28(\mathrm{~s}, 2 \mathrm{H}), 5.87(\mathrm{~d}, J=5.6 \mathrm{~Hz}, 1 \mathrm{H}), 5.48(\mathrm{~d}, J=6.0 \mathrm{~Hz}$, $1 \mathrm{H}), 5.30(\mathrm{~d}, J=5.1 \mathrm{~Hz}, 1 \mathrm{H}), 4.73(\mathrm{q}, J=5.6 \mathrm{~Hz}, 1 \mathrm{H}), 4.18-4.13(\mathrm{~m}, 1 \mathrm{H}), 4.01(\mathrm{td}, J=6.4$, $3.9 \mathrm{~Hz}, 1 \mathrm{H}), 3.82(\mathrm{~s}, 2 \mathrm{H}), 2.84(\mathrm{dd}, J=13.9,5.9 \mathrm{~Hz}, 1 \mathrm{H}), 2.70(\mathrm{dd}, J=13.9,6.9 \mathrm{~Hz}, 1 \mathrm{H}) .{ }^{13} \mathrm{C}$ NMR $\left(100 \mathrm{MHz}\right.$, DMSO- $\left.d_{6}\right) \delta 167.2,156.1,152.7,149.4,140.0,139.2,133.3,131.0,129.7$, 128.6, 127.8, 119.2, 87.6, 83.6, 72.6, 72.5, 35.2, 33.4. HRMS (ESI/TOF-Q) m/z: $[\mathrm{M}+\mathrm{H}]^{+}$ calcd for C18H20N5O5S, 418.1180; found, 418.1189.

9-((3aR,4R,6S,6aS)-2,2-Dimethyl-6-(((naphthalen-2-

ylmethyl)thio)methyl)tetrahydrofuro[3,4-d][1,3]dioxol-4-yl)-9H-purin-6-amine 12

To a solution of 5'-acetylthio-5'-deoxy-2',3'-O-isopropylideneadenosine 10 (90 $\mathrm{mg}, 0.25$ $\mathrm{mmol}$ ) and 2-(bromomethyl)naphtalene $(60 \mathrm{mg}, 0.27 \mathrm{mmol})$ in dry $\mathrm{MeOH}(1.5 \mathrm{ml})$ was added sodium methoxide solution in $\mathrm{MeOH}(5.4 \mathrm{M}, 0.10 \mathrm{ml}, 0.54 \mathrm{mmol})$ under argon atmosphere cooling reaction mixture in the dry ice-acetone bath (bath temperature $-30^{\circ} \mathrm{C}$ ). The reaction mixture was stirred at $-30^{\circ} \mathrm{C}$ for $1 \mathrm{~h}$, then allowed to warm to room temperature and stirred for $3 \mathrm{~h}$. The solvent was evaporated under reduced pressure. The residue was diluted with EtOAc $\left(20 \mathrm{ml}\right.$ ), washed with saturated $\mathrm{NH}_{4} \mathrm{Cl}$ solution, water, dried over anhydrous $\mathrm{Na}_{2} \mathrm{SO}_{4}$ and concentrated. The residue was purified by chromatography on silica gel on Biotage, eluent EtOAc:EtOH 3:1 in petroleum ether, gradient 20-60\% to give $97 \mathrm{mg}(85 \%)$ of the product 12 as a white foam. ${ }^{1} \mathrm{H}$ NMR $\left(300 \mathrm{MHz}, \mathrm{CDCl}_{3}\right) \delta 8.27(\mathrm{~s}, 1 \mathrm{H}), 7.90(\mathrm{~s}, 1 \mathrm{H}), 7.82-7.71(\mathrm{~m}, 3 \mathrm{H})$, $7.61(\mathrm{~s}, 1 \mathrm{H}), 7.49-7.39(\mathrm{~m}, 3 \mathrm{H}), 6.04(\mathrm{~d}, J=2.3 \mathrm{~Hz}, 1 \mathrm{H}), 5.56(\mathrm{~s}, 2 \mathrm{H}), 5.42(\mathrm{dd}, J=6.4,2.3$ $\mathrm{Hz}, 1 \mathrm{H}), 4.95(\mathrm{dd}, J=6.4,3.3 \mathrm{~Hz}, 1 \mathrm{H}), 4.35(\mathrm{td}, J=6.7,3.3 \mathrm{~Hz}, 1 \mathrm{H}), 3.86(\mathrm{~s}, 2 \mathrm{H}), 2.78(\mathrm{dd}, J$ $=13.7,7.1 \mathrm{~Hz}, 1 \mathrm{H}), 2.67(\mathrm{dd}, J=13.7,6.3 \mathrm{~Hz}, 1 \mathrm{H}), 1.57(\mathrm{~s}, 3 \mathrm{H}), 1.35(\mathrm{~s}, 3 \mathrm{H}) .{ }^{13} \mathrm{C} \mathrm{NMR}(100$ $\left.\mathrm{MHz}, \mathrm{CDCl}_{3}\right) \delta 155.7,153.2,149.3,140.0,135.2,133.3,132.7,128.6,127.8,127.8,127.5$, $127.1,126.4,126.0,120.4,114.6,90.9,86.7,84.1,83.9,36.9,33.3,27.2,25.4$. HRMS (ESI/TOF-Q) m/z: [M + H] ${ }^{+}$calcd for C24H26N5O3S, 464.1751; found, 464.1777. 
$(2 R, 3 R, 4 S, 5 S)-2-(6-A m i n o-9 H-p u r i n-9-y l)-5-((($ naphthalen-2-

ylmethyl)thio)methyl)tetrahydro furan-3,4-diol 2b

Acetonide 12 ( $80 \mathrm{mg}, 0.17 \mathrm{mmol}$ ) was dissolved in ice-cold $\mathrm{HCOOH}$ solution in water $(50 \%$, $1 \mathrm{ml})$. The reaction mixture was stirred at $30^{\circ} \mathrm{C}$ for 3 days. The solvent was evaporated, then the residue was co-evaporated with $\mathrm{EtOH}$ to remove $\mathrm{HCOOH}$. The residue was chromatographed on $\mathrm{C} 18$ silica on Biotage, eluent acetonitrile in $0.1 \% \mathrm{HCOOH}$, gradient 5$50 \%$. After concentration an oil was obtained. The oil was dissolved in water-acetonitrile mixture $(1: 1,2 \mathrm{ml})$; the precipitate was formed after sonication. The precipitate was filtered off and dried to give $34 \mathrm{mg}(47 \%)$ of the product $\mathbf{2 b}$ as a white solid. HPLC purity $98 \%$. ${ }^{1} \mathrm{H}$ NMR $\left(400 \mathrm{MHz}, \mathrm{DMSO}-d_{6}\right) \delta 8.34(\mathrm{~s}, 1 \mathrm{H}), 8.10(\mathrm{~s}, 1 \mathrm{H}), 7.90-7.81(\mathrm{~m}, 2 \mathrm{H}), 7.81-7.74(\mathrm{~m}, 1 \mathrm{H})$, $7.70-7.66(\mathrm{~m}, 1 \mathrm{H}), 7.52-7.46(\mathrm{~m}, 2 \mathrm{H}), 7.43(\mathrm{dd}, J=8.4,1.7 \mathrm{~Hz}, 1 \mathrm{H}), 7.29$ (br s, 2H), 5.89 $(\mathrm{d}, J=5.2 \mathrm{~Hz}, 1 \mathrm{H}), 5.49(\mathrm{~d}, J=5.9 \mathrm{~Hz}, 1 \mathrm{H}), 5.30(\mathrm{~d}, J=5.4 \mathrm{~Hz}, 1 \mathrm{H}), 4.73(\mathrm{q}, J=5.5 \mathrm{~Hz}, 1 \mathrm{H})$, $4.20-4.15(\mathrm{~m}, 1 \mathrm{H}), 4.06-4.01(\mathrm{~m}, 1 \mathrm{H}), 3.90(\mathrm{~s}, 2 \mathrm{H}), 2.84(\mathrm{dd}, J=13.9,5.7 \mathrm{~Hz}, 1 \mathrm{H}), 2.69$ $(\mathrm{dd}, J=13.9,6.9 \mathrm{~Hz}, 1 \mathrm{H}) .{ }^{13} \mathrm{C}$ NMR $\left(100 \mathrm{MHz}, \mathrm{DMSO}-d_{6}\right) \delta 156.1,152.7,149.4,140.0,136.0$, $132.8,132.0,128.1,127.5,127.5,127.3,127.1,126.2,125.8,119.2,87.7,83.8,72.7,72.6$, 35.9, 33.3. HRMS (ESI/TOF-Q) $\mathrm{m} / \mathrm{z}$ : $[\mathrm{M}+\mathrm{H}]^{+}$calcd for $\mathrm{C} 21 \mathrm{H} 22 \mathrm{~N} 5 \mathrm{O} 3 \mathrm{~S}, 424.1438$; found, 424.1443 .

9-((3aR,4R,6S,6aS)-6-((But-3-yn-1-ylthio)methyl)-2,2-dimethyltetrahydrofuro[3,4d] $[1,3]$ dioxol-4-yl)-9H-purin-6-amine 13

To a solution of $5^{\prime}$-acetylthio-5'-deoxy-2',3'-O-isopropylideneadenosine $10(0.30 \mathrm{~g}, 0.82$ $\mathrm{mmol})$ in dry $\mathrm{MeOH}(3 \mathrm{ml})$ was added 4-bromobut-1-yne $(85 \mu \mathrm{l}, 0.90 \mathrm{mmol})$ under argon atmosphere and the mixture was cooled in the dry ice-acetone bath (bath temperature $-30^{\circ} \mathrm{C}$ ), then sodium methoxide solution in $\mathrm{MeOH}(5.4 \mathrm{M}, 0.32 \mathrm{ml}, 1.7 \mathrm{mmol})$ was added dropwise. The reaction mixture was stirred at $-30^{\circ} \mathrm{C}$ for $1 \mathrm{~h}$, then allowed to warm to room temperature and stirred for $16 \mathrm{~h}$. The solvent was evaporated under reduced pressure. The residue was diluted with EtOAc $(40 \mathrm{ml})$, washed with saturated $\mathrm{NH}_{4} \mathrm{Cl}$ solution, water, dried over anhydrous $\mathrm{Na}_{2} \mathrm{SO}_{4}$ and concentrated. The residue was purified by chromatography on silica gel on Biotage, eluent EtOAc:EtOH 3:1 in petroleum ether, gradient $50-100 \%$ to give $0.15 \mathrm{~g}(48 \%)$ of the product 13 as a colorless oil. ${ }^{1} \mathrm{H}$ NMR $\left(400 \mathrm{MHz}, \mathrm{CDCl}_{3}\right) \delta 8.34(\mathrm{~s}, 1 \mathrm{H}), 7.92(\mathrm{~s}, 1 \mathrm{H})$, $6.07(\mathrm{~d}, J=2.2 \mathrm{~Hz}, 1 \mathrm{H}), 5.90(\mathrm{~s}, 2 \mathrm{H}), 5.50(\mathrm{dd}, J=6.4,2.2 \mathrm{~Hz}, 1 \mathrm{H}), 5.07$ (dd, $J=6.4,3.2 \mathrm{~Hz}$, $1 \mathrm{H}), 4.39$ (td, $J=6.9,3.2 \mathrm{~Hz}, 1 \mathrm{H}), 2.92(\mathrm{dd}, J=13.7,7.3 \mathrm{~Hz}, 1 \mathrm{H}), 2.85$ (dd, $J=13.7,6.4 \mathrm{~Hz}$, $1 \mathrm{H}), 2.68(\mathrm{t}, J=7.3 \mathrm{~Hz}, 2 \mathrm{H}), 2.41(\mathrm{td}, J=7.3,2.6 \mathrm{~Hz}, 2 \mathrm{H}), 2.00(\mathrm{t}, J=2.6 \mathrm{~Hz}, 1 \mathrm{H}), 1.61(\mathrm{~s}$, $3 \mathrm{H}), 1.39(\mathrm{~s}, 3 \mathrm{H}) .{ }^{13} \mathrm{C} \mathrm{NMR}\left(100 \mathrm{MHz}, \mathrm{CDCl}_{3}\right) \delta 155.8,153.3,149.3,140.2,120.4,114.7$, 91.0, 87.0, 84.2, 83.9, 82.4, 69.8, 34.5, 31.5, 27.2, 25.5, 20.0. HRMS (ESI/TOF-Q) m/z: [M + $\mathrm{H}]^{+}$calcd for C17H22N5O3S, 376.1438; found, 376.1456 .

9-((3aR,4R,6S,6aS)-6-(((2-(1H-1,2,3-Triazol-4-yl)ethyl)thio)methyl)-2,2dimethyltetrahydrofuro[3,4-d][1,3]dioxol-4-yl)-9H-purin-6-amine 14

To a solution alkyne $13(0.14 \mathrm{~g}, 0.37 \mathrm{mmol})$ and copper (I) iodide $(4.0 \mathrm{mg}, 0.021 \mathrm{mmol})$ in DMF:MeOH mixture $(9: 1,1 \mathrm{ml})$ under argon atmosphere was added trimethylsilyl azide (74 $\mu 1,0.56 \mathrm{mmol})$. The reaction mixture was stirred in a closed vial at $100^{\circ} \mathrm{C}$ for $10 \mathrm{~h}$. The mixture was cooled to room temperature, filtered through a celite pad, and concentrated. The residue was purified by chromatography on silica gel on Biotage, eluent EtOAc:EtOH 3:1 in petroleum ether, gradient $20-50 \%$ to give $77 \mathrm{mg}(49 \%)$ of the product 14 as a white solid. ${ }^{1} \mathrm{H}$ NMR (400 $\left.\mathrm{MHz} \mathrm{CDCl}_{3}\right) \delta 13.67$ (br s, 1H), $8.37(\mathrm{~s}, 1 \mathrm{H}), 8.00(\mathrm{~s}, 1 \mathrm{H}), 7.48(\mathrm{~s}, 1 \mathrm{H}), 6.30$ (br s, 2H), 6.11 $(\mathrm{d}, J=2.3 \mathrm{~Hz}, 1 \mathrm{H}), 5.47(\mathrm{dd}, J=6.4,2.3 \mathrm{~Hz}, 1 \mathrm{H}), 5.06(\mathrm{dd}, J=6.4,3.3 \mathrm{~Hz}, 1 \mathrm{H}), 4.43$ (td, $J=$ $6.4,3.3 \mathrm{~Hz}, 1 \mathrm{H}), 3.00-2.91(\mathrm{~m}, 3 \mathrm{H}), 2.90-2.82(\mathrm{~m}, 3 \mathrm{H}), 1.62(\mathrm{~s}, 3 \mathrm{H}), 1.40(\mathrm{~s}, 3 \mathrm{H}) .{ }^{13} \mathrm{C}$ NMR $\left(100 \mathrm{MHz}, \mathrm{CDCl}_{3}\right) \delta 155.9,153.3,149.2,140.0,119.9,114.8,90.9,87.2,84.3,83.7,34.7,32.4$, 
27.2, 26.0, 25.5. HRMS (ESI/TOF-Q) m/z: $[\mathrm{M}+\mathrm{H}]^{+}$calcd for $\mathrm{C} 17 \mathrm{H} 23 \mathrm{~N} 8 \mathrm{O} 3 \mathrm{~S}, 419.1608$; found, 419.1617.

(2S,3S,4R,5R)-2-(((2-(1H-1,2,3-Triazol-4-yl)ethyl)thio)methyl)-5-(6-amino-9H-purin-9yl)tetrahydrofuran-3,4-diol 3a

Acetonide 14 (90 mg, $0.22 \mathrm{mmol}$ ) was dissolved in ice-cold $\mathrm{HCOOH}$ solution in water $(50 \%$, $1 \mathrm{ml})$. The reaction mixture was stirred at room temperature for 3 days. The solvent was evaporated, then the residue co-evaporated with $\mathrm{EtOH}$ to remove $\mathrm{HCOOH}$. The residue was chromatographed on $\mathrm{C} 18$ silica on Biotage, eluent acetonitrile in $0.1 \% \mathrm{HCOOH}$, gradient 5$50 \%$, and then freeze-dried to give $58 \mathrm{mg}(64 \%)$ of the product 3a as a white solid, which contains 1 equivalent of $\mathrm{HCOOH}(\mathrm{NMR})$. HPLC purity $96 \% .{ }^{1} \mathrm{H}$ NMR (400 MHz, DMSO- $\left.d_{6}\right)$ $\delta 14.57$ (br s, $1 \mathrm{H}), 8.35(\mathrm{~s}, 1 \mathrm{H}), 8.15(\mathrm{~s}, 1 \mathrm{H}), 8.14(\mathrm{~s}, 1 \mathrm{H}, \underline{\mathrm{HCOOH}}), 7.53(\mathrm{~s}, 1 \mathrm{H}), 7.28$ (br s, $2 \mathrm{H}), 5.89(\mathrm{~d}, J=5.8 \mathrm{~Hz}, 1 \mathrm{H}), 5.49(\mathrm{br} \mathrm{s}, 1 \mathrm{H}), 5.32(\mathrm{br} \mathrm{s}, 1 \mathrm{H}), 4.75(\mathrm{t}, J=5.2 \mathrm{~Hz}, 1 \mathrm{H}), 4.15$ (t, $J=4.5 \mathrm{~Hz}, 1 \mathrm{H}), 4.02(\mathrm{ddd}, J=7.0,5.8,3.7 \mathrm{~Hz}, 1 \mathrm{H}), 2.94(\mathrm{dd}, J=13.9,5.8 \mathrm{~Hz}, 1 \mathrm{H}), 2.90-$ $2.76(\mathrm{~m}, 5 \mathrm{H}) .{ }^{13} \mathrm{C}$ NMR $\left(100 \mathrm{MHz}, \mathrm{DMSO}-d_{6}\right) \delta 163.1(\mathrm{HCOOH}), 156.1,152.7,149.5,139.9$, 119.2, 87.4, 84.0, 72.6, 33.9, 31.3. HRMS (ESI/TOF-Q) $\mathrm{m} / \mathrm{z}:[\mathrm{M}+\mathrm{H}]^{+}$calcd for C14H19N8O3S, 379.1295; found, 379.1303.

Ethyl 4-(((3aS $4 S, 6 R, 6 \mathrm{a} R)-6$-(6-amino-9H-purin-9-yl)-2,2-dimethyltetrahydrofuro[3,4d] [1,3]dioxol-4-yl)methyl)thio)-3-oxobutanoate 15

To a solution of $5^{\prime}$-acetylthio-5'-deoxy-2',3'-O-isopropylideneadenosine 10 (50 mg, 0.14 $\mathrm{mmol})$ in dry $\mathrm{MeOH}(1.2 \mathrm{ml})$ under argon atmosphere was added ethyl chloroacetate $(19 \mu \mathrm{l}$, $0.14 \mathrm{mmol}$ ) and the mixture was cooled in the ice bath with $\mathrm{NaCl}$ (bath temperature $-15^{\circ} \mathrm{C}$ ), then sodium methoxide solution in $\mathrm{MeOH}(5.4 \mathrm{M}, 56 \mu \mathrm{l}, 0.30 \mathrm{mmol})$ was added dropwise. The reaction mixture was stirred at $-10^{\circ} \mathrm{C}$ for $1 \mathrm{~h}$, then allowed to warm to room temperature and stirred for $3 \mathrm{~h}$. The solvent was evaporated under reduced pressure. The residue was diluted with EtOAc $(15 \mathrm{ml})$, washed with $\mathrm{NH}_{4} \mathrm{Cl}$ saturated solution, water, dried over anhydrous $\mathrm{Na}_{2} \mathrm{SO}_{4}$ and concentrated. The residue was purified by chromatography on silica gel on Biotage, eluent EtOAc:EtOH 3:1 in petroleum ether, gradient 20-80\% to give $27 \mathrm{mg}$ (44\%) of the product 15 as a colorless oil, which contains methyl ester impurity $(8 \%$ based on UPLC data) and enol form of the product ( 0.08 equivalent based on ${ }^{1} \mathrm{H}-\mathrm{NMR}$ data $12.02(\mathrm{~s}, 1 \mathrm{H}), 6.06$ $(\mathrm{s}, 1 \mathrm{H})$ ). Used without further purification. ${ }^{1} \mathrm{H} \mathrm{NMR}\left(300 \mathrm{MHz}, \mathrm{CDCl}_{3}\right) \delta 8.34(\mathrm{~s}, 1 \mathrm{H}), 7.90$ $(\mathrm{s}, 1 \mathrm{H}), 6.05(\mathrm{~d}, J=2.1 \mathrm{~Hz}, 1 \mathrm{H}), 5.90(\mathrm{br} \mathrm{s}, 2 \mathrm{H}), 5.47$ (dd, $J=6.4,2.1 \mathrm{~Hz}, 1 \mathrm{H}), 5.05$ (dd, $J=$ 6.4, $3.4 \mathrm{~Hz}, 1 \mathrm{H}), 4.36(\mathrm{td}, J=6.8,3.4 \mathrm{~Hz}, 1 \mathrm{H}), 4.16(\mathrm{q}, J=7.1 \mathrm{~Hz}, 2 \mathrm{H}), 3.57(\mathrm{~s}, 2 \mathrm{H}), 3.36(\mathrm{~s}$, 2H), $2.87(\mathrm{dd}, J=13.9,6.7 \mathrm{~Hz}, 1 \mathrm{H}), 2.79(\mathrm{dd}, J=13.9,6.9 \mathrm{~Hz}, 1 \mathrm{H}), 1.60(\mathrm{~s}, 3 \mathrm{H}), 1.38(\mathrm{~s}, 3 \mathrm{H})$, $1.24(\mathrm{t}, J=7.1 \mathrm{~Hz}, 2 \mathrm{H})$. LCMS (ESI+) m/z: $[\mathrm{M}+\mathrm{H}]^{+}$calcd for C19H26N5O6S 452.2; found 452.4 .

$(2 R, 3 R, 4 S, 5 S)-2-(6-A m i n o-9 H$-purin-9-yl)-5-((((5-hydroxy-1H-pyrazol-3yl)methyl)thio)methyl)tetrahydrofuran-3,4-diol 3b

To a solution of ethyl acetoacetate derivative $15(0.10 \mathrm{~g}, 0.22 \mathrm{mmol})$ in absolute EtOH $(0.7 \mathrm{ml})$ under argon atmosphere was added hydrazine hydrate $(22 \mu 1,0.44 \mathrm{mmol})$ and the reaction mixture was stirred at room temperature for $2 \mathrm{~h}$. The reaction mixture was concentrated under reduced pressure, then dissolved in ice-cold $\mathrm{HCOOH}$ solution in water $(50 \%, 1 \mathrm{ml})$. The reaction mixture was stirred at room temperature for $16 \mathrm{~h}$. The solvent was evaporated, then the residue was co-evaporated with $\mathrm{EtOH}$ to remove $\mathrm{HCOOH}$. The residue was chromatographed on $\mathrm{C} 18$ silica on Biotage, eluent acetonitrile in $0.1 \% \mathrm{HCOOH}$, gradient 5$50 \%$, and then freeze-dried to give $20 \mathrm{mg}(28 \%)$ of the product as a white solid. HPLC purity 97\%. ${ }^{1} \mathrm{H}$ NMR $\left(400 \mathrm{MHz}\right.$, Methanol- $\left.d_{4}\right) \delta 8.30(\mathrm{~s}, 1 \mathrm{H}), 8.22(\mathrm{~s}, 1 \mathrm{H}), 8.11(\mathrm{~s}, 1 \mathrm{H}), 6.00(\mathrm{~d}, J=$ $5.1 \mathrm{~Hz}, 1 \mathrm{H}), 4.78(\mathrm{t}, J=5.1 \mathrm{~Hz}, 1 \mathrm{H}), 4.31(\mathrm{t}, J=5.1 \mathrm{~Hz}, 1 \mathrm{H}), 4.20(\mathrm{q}, J=5.6 \mathrm{~Hz}, 1 \mathrm{H}), 3.67$ 
$(\mathrm{d}, J=1.3 \mathrm{~Hz}, 2 \mathrm{H}), 2.98(\mathrm{dd}, J=14.2,5.4 \mathrm{~Hz}, 1 \mathrm{H}), 2.89(\mathrm{dd}, J=14.2,6.2 \mathrm{~Hz}, 1 \mathrm{H}) .{ }^{13} \mathrm{C}$ NMR $\left(100 \mathrm{MHz}\right.$, Methanol- $\left.d_{4}\right) \delta 164.9,162.4,157.2,153.8,150.6,145.1,141.5,120.6,90.2,85.5$, 74.8, 74.0, 34.8, 28.2. HRMS (ESI/TOF-Q) m/z: $[\mathrm{M}+\mathrm{H}]^{+}$calcd for C14H18N7O4S, 380.1135; found, 380.1138 .

\subsection{Synthesis of SAM analogues $3 \mathrm{c}, 4 \mathrm{~b}$}

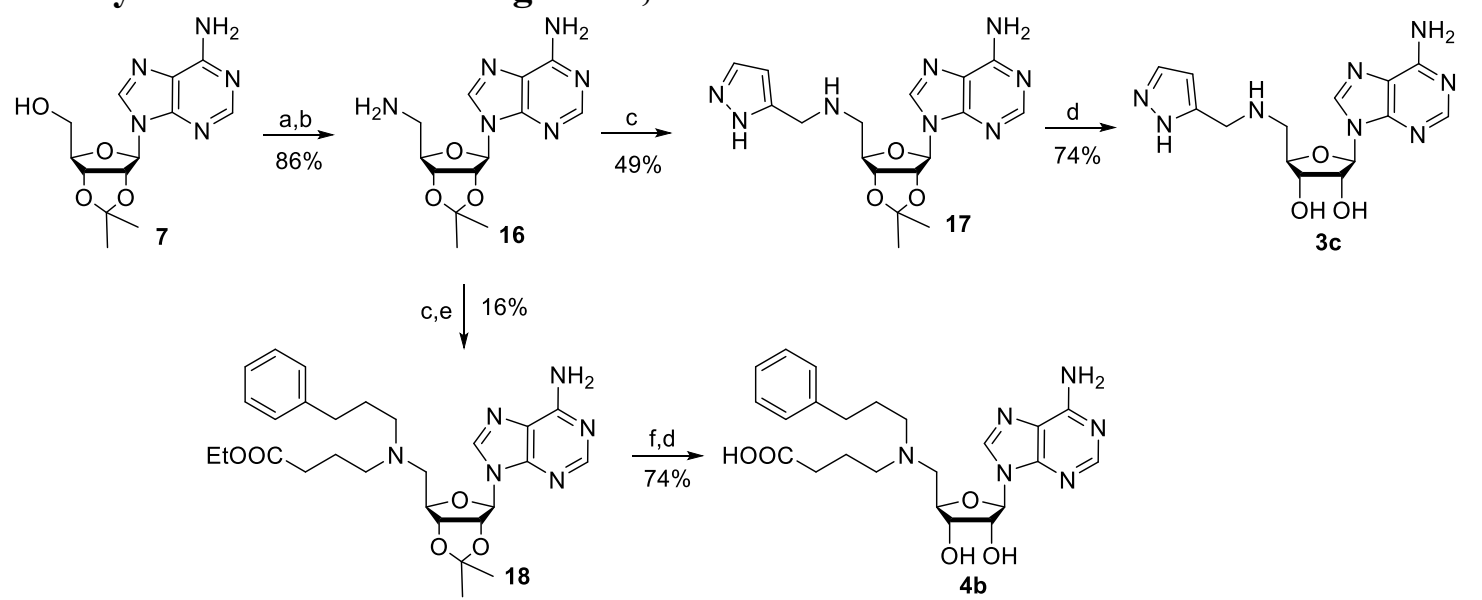

Reagents and conditions: (a) DPPA, DBU, $\mathrm{NaN}_{3}, 15$-crown- 5 , THF, $90^{\circ} \mathrm{C}$; (b) $\mathrm{H}_{2}, 10 \% \mathrm{Pd} / \mathrm{C}, \mathrm{EtOAc}, \mathrm{MeOH}$, rt rt; (c) appropriate aldehyde, $\mathrm{AcOH}, \mathrm{DCE}, \mathrm{MeOH}$, then $\mathrm{Na}(\mathrm{OAc})_{3} \mathrm{BH}, \mathrm{Et}_{3} \mathrm{~N}$, rt; (d) $\mathrm{HCOOH}$, water, rt or $50^{\circ} \mathrm{C}$; (e) ethyl 4-bromobutyrate, $\mathrm{K}_{2} \mathrm{CO}_{3}$, DMF, $50^{\circ} \mathrm{C}$; (f) $\mathrm{LiOH}$, THF, water, rt.

9-((3aR,4R,6R,6aR)-6-(Aminomethyl)-2,2-dimethyltetrahydrofuro[3,4-d][1,3]dioxol-4-yl)9H-purin-6-amine 16

To a suspension of 2',3'-O-isopropylideneadenosine 7 (1.00 g, $3.25 \mathrm{mmol}$ ) in 1,4-dioxane (10 $\mathrm{ml})$ was added diphenylphosphoryl azide $(1.10 \mathrm{ml}, 5.10 \mathrm{mmol})$ and DBU $(970 \mu 1,6.50 \mathrm{mmol})$ under argon atmosphere at room temperature. The solution was stirred for $2 \mathrm{~h}$, then sodium azide $(1.06 \mathrm{~g}, 16.3 \mathrm{mmol})$ and 15 -crown-5 $(65.0 \mu \mathrm{L}, 0.326 \mathrm{mmol})$ were added, and the reaction mixture was heated at $90^{\circ} \mathrm{C}$ for $3 \mathrm{~h}$, then stirred at room temperature for $14 \mathrm{~h}$. The solid was removed by filtration through a pad of celite, washing with EtOAc and DCM. The filtrate was concentrated and the crude product was purified by chromatography on silica gel on Biotage, eluent EtOAc:EtOH 3:1 in petroleum ether, gradient 20-80\% to give $0.97 \mathrm{~g} \mathrm{(90 \% )} \mathrm{of} \mathrm{azide}$ derivative as a yellow foam. ${ }^{1} \mathrm{H}$ NMR $\left(300 \mathrm{MHz}, \mathrm{CDCl}_{3}\right) \delta 8.36(\mathrm{~s}, 1 \mathrm{H}), 7.91(\mathrm{~s}, 1 \mathrm{H}), 6.11(\mathrm{~d}$, $J=2.3 \mathrm{~Hz}, 1 \mathrm{H}), 5.80$ (br s, 2H), 5.46 (dd, $J=6.4,2.3 \mathrm{~Hz}, 1 \mathrm{H}), 5.06$ (dd, $J=6.4,3.4 \mathrm{~Hz}, 1 \mathrm{H})$, $4.38(\mathrm{td}, J=5.8,3.4 \mathrm{~Hz}, 1 \mathrm{H}), 3.64-3.51(\mathrm{~m}, 2 \mathrm{H}), 1.62(\mathrm{~s}, 3 \mathrm{H}), 1.39(\mathrm{~s}, 3 \mathrm{H})$. This azide $(970$ $\mathrm{mg}, 2.92 \mathrm{mmol})$ was dissolved in ethanol $(17 \mathrm{ml})$ and EtOAc $(3 \mathrm{ml})$, the solution was degassed by bubbling argon for $10 \mathrm{~min}$, then $10 \%$ palladium on activated charcoal was added $(0.1 \mathrm{~g})$. The reaction mixture was placed under an atmosphere of $\mathrm{H}_{2}$ (bubbling) at room temperature for $3 \mathrm{~h}$. The reaction mixture was filtered through a pad of celite. The solvent was evaporated to give $850 \mathrm{mg}\left(86 \%\right.$ in two steps) product 16 as a white solid. ${ }^{1} \mathrm{H}$ NMR $\left(300 \mathrm{MHz}, \mathrm{CDCl}_{3}\right) \delta$ $8.34(\mathrm{~s}, 1 \mathrm{H}), 7.92(\mathrm{~s}, 2 \mathrm{H}), 6.03(\mathrm{~d}, J=3.0 \mathrm{~Hz}, 1 \mathrm{H}), 5.70(\mathrm{br} \mathrm{s}, 2 \mathrm{H}), 5.47$ (dd, $J=6.5,3.0 \mathrm{~Hz}$, $1 \mathrm{H}), 5.02$ (dd, $J=6.5,3.5 \mathrm{~Hz}, 1 \mathrm{H}), 4.28-4.22(\mathrm{~m}, 1 \mathrm{H}), 3.04$ (dd, $J=13.4,4.5 \mathrm{~Hz}, 1 \mathrm{H}), 2.95$ $(\mathrm{dd}, J=13.4,5.9 \mathrm{~Hz}, 1 \mathrm{H}), 1.62(\mathrm{~s}, 3 \mathrm{H}), 1.60(\mathrm{br} \mathrm{s}, 2 \mathrm{H}), 1.39(\mathrm{~s}, 3 \mathrm{H})$. Data are consistent with literature values. ${ }^{4}$

9-((3a $R, 4 R, 6 R, 6 \mathrm{a} R)-6-((((1 H-P y r a z o l-3-y 1) m e t h y l) a m i n o) m e t h y l)-2,2-$ dimethyltetrahydrofuro[3,4-d][1,3]dioxol-4-yl)-9H-purin-6-amine 17

Amine 16 (0.14 g, $0.46 \mathrm{mmol})$ and $1 H$-pyrazole-5-carbaldehyde (40 mg, $0.42 \mathrm{mmol})$ was mixed in DCE $(2 \mathrm{ml})$ and $\mathrm{MeOH}(1 \mathrm{ml})$, then acetic acid $(24 \mu \mathrm{l}, 0.42 \mathrm{mmol})$ was added under argon at room temperature and the reaction mixture was stirred for $1 \mathrm{~h}$. Sodium 
triacetoxyborohydride $(0.18 \mathrm{~g}, 0.84 \mathrm{mmol})$ was added in portions $-97 \mathrm{mg}$, then after $2.5 \mathrm{~h} 30$ $\mathrm{mg}$, after additional $1 \mathrm{~h} 20 \mathrm{mg}$, after additional $1 \mathrm{~h} 20 \mathrm{mg}$, after $16 \mathrm{~h} 10 \mathrm{mg}$ and stirred for $1 \mathrm{~h}$. The mixture was diluted with EtOAc $(20 \mathrm{ml})$ and saturated $\mathrm{NaHCO}_{3}(5 \mathrm{ml})$ was added. Organic layer was separated and water layer was extracted with EtOAc $(2 \times 10 \mathrm{ml})$, then brine was added to water layer and was extracted with EtOAc $(10 \mathrm{ml})$. The combined organic layers were dried over anhydrous $\mathrm{Na}_{2} \mathrm{SO}_{4}$, filtered, and concentrated under reduced pressure. The residue was purified by chromatography on silica gel, eluent $10 \% \mathrm{MeOH}$ in DCM to give $79 \mathrm{mg}(49 \%)$ of the product 17 as a white foam. ${ }^{1} \mathrm{H}$ NMR $\left(300 \mathrm{MHz}, \mathrm{CDCl}_{3}\right) \delta 8.15(\mathrm{~s}, 1 \mathrm{H}), 7.90(\mathrm{~s}, 1 \mathrm{H}), 7.50$ $(\mathrm{d}, J=2.0 \mathrm{~Hz}, 1 \mathrm{H}), 6.15(\mathrm{~d}, J=2.0 \mathrm{~Hz}, 1 \mathrm{H}), 5.99(\mathrm{~d}, J=3.2 \mathrm{~Hz}, 1 \mathrm{H}), 5.96(\mathrm{br} \mathrm{s}, 2 \mathrm{H}), 5.47(\mathrm{dd}$, $J=6.4,3.2 \mathrm{~Hz}, 1 \mathrm{H}), 5.06(\mathrm{dd}, J=6.4,3.1 \mathrm{~Hz}, 1 \mathrm{H}), 4.46-4.39(\mathrm{~m}, 1 \mathrm{H}), 3.92(\mathrm{~d}, J=14.1 \mathrm{~Hz}$, $1 \mathrm{H}), 3.85(\mathrm{~d}, J=14.1 \mathrm{~Hz}, 1 \mathrm{H}), 3.13($ br s, $1 \mathrm{H}), 2.98$ (dd, $J=12.6,4.4 \mathrm{~Hz}, 1 \mathrm{H})$, ), 2.93 (dd, $J=$ 12.6, $5.7 \mathrm{~Hz}, 1 \mathrm{H}), 1.61(\mathrm{~s}, 3 \mathrm{H}), 1.37(\mathrm{~s}, 3 \mathrm{H})$. The signal of pyrazole NH proton was not observed by NMR due to exchange with residual water protons. ${ }^{13} \mathrm{C} \mathrm{NMR}\left(100 \mathrm{MHz}, \mathrm{CDCl}_{3}\right)$ $\delta 155.8,153.1,149.1,146.4,140.1,133.7,120.0,114.6,104.1,91.2,85.8,83.6,82.5,50.7$, 45.9, 27.3, 25.4. HRMS (ESI/TOF-Q) m/z: $[\mathrm{M}+\mathrm{H}]^{+}$calcd for $\mathrm{C} 17 \mathrm{H} 23 \mathrm{~N} 8 \mathrm{O} 3,387.1888$; found, 387.1888 .

$(2 R, 3 S, 4 R, 5 R)-2-((((1 H$-Pyrazol-3-yl)methyl)amino)methyl)-5-(6-amino-9H-purin-9yl)tetrahydrofuran-3,4-diol 3c

Acetonide 17 ( $79 \mathrm{mg}, 0.20 \mathrm{mmol}$ ) was dissolved in ice-cold $\mathrm{HCOOH}$ solution in water $(50 \%$, $1 \mathrm{ml}$ ). The reaction mixture was stirred at room temperature for 3 days. The solvent was evaporated, then the residue was co-evaporated with $\mathrm{EtOH}$ to remove $\mathrm{HCOOH}$. The residue was chromatographed on $\mathrm{C} 18$ silica on Biotage, eluent acetonitrile in $0.1 \% \mathrm{HCOOH}$, gradient $5-50 \%$, then freeze-dried to give $59 \mathrm{mg}(74 \%)$ of the product $3 \mathrm{c}$ as a glass-like solid, which contains 1 equivalent of $\mathrm{HCOOH}(\mathrm{NMR})$. HPLC purity $97 \%$. ${ }^{1} \mathrm{H}$ NMR (400 MHz, DMSO- $\left.d_{6}\right)$ $\delta 8.33(\mathrm{~s}, 2 \mathrm{H}), 8.24(\mathrm{~s}, 1 \mathrm{H}, \underline{\mathrm{HCOOH}}), 8.05(\mathrm{~s}, 1 \mathrm{H}), 7.58(\mathrm{~d}, J=1.9 \mathrm{~Hz}, 1 \mathrm{H}), 7.31(\mathrm{br} \mathrm{s}, 2 \mathrm{H})$, $6.22(\mathrm{~d}, J=1.9 \mathrm{~Hz}, 1 \mathrm{H}), 5.87(\mathrm{~d}, J=6.0 \mathrm{~Hz}, 1 \mathrm{H}), 4.69(\mathrm{t}, J=5.5 \mathrm{~Hz}, 1 \mathrm{H}), 4.21-4.16(\mathrm{~m}, 1 \mathrm{H})$, $4.12-4.05(\mathrm{~m}, 1 \mathrm{H}), 3.90(\mathrm{~d}, J=14.0 \mathrm{~Hz}, 1 \mathrm{H}), 3.86(\mathrm{~d}, J=14.0 \mathrm{~Hz}, 1 \mathrm{H}), 3.03-2.90(\mathrm{~m}, 2 \mathrm{H})$. The signals of exchangeable protons from two hydroxyl groups and two secondary amine groups (including pyrazole $\mathrm{NH}$ ) were not observed by NMR due to fast exchange with residual water protons. ${ }^{13} \mathrm{C}$ NMR $\left(100 \mathrm{MHz}, \mathrm{DMSO}-d_{6}\right) \delta 164.2(\mathrm{HCOOH}), 156.2,152.6,149.2,145.2$, 140.3, 132.4, 119.4, 103.9, 88.1, 82.8, 72.7, 71.5, 50.0, 45.0. HRMS (ESI/TOF-Q) m/z: [M + $\mathrm{H}]^{+}$calcd for $\mathrm{C} 14 \mathrm{H} 19 \mathrm{~N} 8 \mathrm{O} 3,347.1575$; found, 347.1580 .

Ethyl 4-((( $\quad(3 \mathrm{a} R, 4 R, 6 R, 6 \mathrm{a} R)-6-(6-A m i n o-9 H$-purin-9-yl)-2,2-dimethyltetrahydrofuro[3,4d][1,3]dioxol-4-yl)methyl)(phenethyl)amino)butanoate 18

To a solution of 2-phenylacetaldehyde $(40 \mathrm{mg}, 0.33 \mathrm{mmol})$ in dry DCM $(1 \mathrm{ml})$ was added a solution of amine $16(102 \mathrm{mg}, 0.333 \mathrm{mmol})$ in DCM $(1 \mathrm{ml})$ under argon atmosphere at room temperature. The mixture was stirred for $30 \mathrm{~min} \mathrm{Et}_{3} \mathrm{~N}(67.0 \mu \mathrm{l}, 0.499 \mathrm{mmol})$ was added into the solution, then sodium triacetoxyborohydride $(102 \mathrm{mg}, 0.500 \mathrm{mmol})$ was added in 4 portions over $20 \mathrm{~min}$ and the mixture stirred at room temperature for $24 \mathrm{~h}$. The reaction solution was quenched with saturated $\mathrm{NaHCO}_{3}(10 \mathrm{ml})$, extracted with EtOAc $(30 \mathrm{ml})$, dried over anhydrous $\mathrm{Na}_{2} \mathrm{SO}_{4}$, filtered and concentrated under reduced pressure. The residue was purified by chromatography on silica gel on Biotage, eluent EtOAc:EtOH 3:1+2\% $\mathrm{NH}_{4} \mathrm{OH}$ in petroleum ether, gradient $40-70 \%$ to give $61 \mathrm{mg}$ of the secondary amine product as a white foam, which contains impurities. Used in the next step without additional purification. ${ }^{1} \mathrm{H}$ NMR $(300 \mathrm{MHz}$, $\left.\mathrm{CDCl}_{3}\right) \delta 8.32(\mathrm{~s}, 1 \mathrm{H}), 7.87(\mathrm{~s}, 1 \mathrm{H}), 7.36-7.02(\mathrm{~m}, 5 \mathrm{H}), 6.00(\mathrm{~d}, J=3.1 \mathrm{~Hz}, 1 \mathrm{H}), 5.67$ (br s, $2 \mathrm{H}), 5.43(\mathrm{dd}, J=6.5,3.1 \mathrm{~Hz}, 1 \mathrm{H}), 5.00(\mathrm{dd}, J=6.5,3.4 \mathrm{~Hz}, 1 \mathrm{H}), 4.38-4.32(\mathrm{~m}, 1 \mathrm{H}), 3.01-$ $2.83(\mathrm{~m}, 4 \mathrm{H}), 2.83-2.71(\mathrm{~m}, 2 \mathrm{H}), 1.82(\mathrm{br} \mathrm{s}, 1 \mathrm{H}), 1.61(\mathrm{~s}, 3 \mathrm{H}), 1.38(\mathrm{~s}, 3 \mathrm{H})$. LCMS (ESI+) $\mathrm{m} / \mathrm{z}:[\mathrm{M}+\mathrm{H}]^{+} 411.40$. To this amine solution in dry DMF $(0.4 \mathrm{ml})$ under argon atmosphere was 
added potassium carbonate $(29 \mathrm{mg}, 0.21 \mathrm{mmol})$, followed by ethyl 4-bromobutyrate $(26 \mu \mathrm{l}$, $0.18 \mathrm{mmol}$ ). The reaction mixture was stirred in a sealed vial at $50^{\circ} \mathrm{C}$ for $72 \mathrm{~h}$. The reaction mixture was concentrated under reduced pressure. The residue was purified by chromatography on Grace amino-modified silica gel on Biotage, eluent EtOAc:EtOH 3:1 in petroleum ether, gradient $10-60 \%$ to give $28 \mathrm{mg}$ (16\% in two steps) of the product 18 as a white foam. ${ }^{1} \mathrm{H}$ NMR $\left(400 \mathrm{MHz}, \mathrm{CDCl}_{3}\right) \delta 8.37(\mathrm{~s}, 1 \mathrm{H}), 7.90(\mathrm{~s}, 1 \mathrm{H}), 7.27-7.21(\mathrm{~m}, 2 \mathrm{H}), 7.19-7.13(\mathrm{~m}, 1 \mathrm{H}), 7.13$ $-7.08(\mathrm{~m}, 2 \mathrm{H}), 6.04$ (d, $J=2.2 \mathrm{~Hz}, 1 \mathrm{H}), 5.60$ (br s, 2H), 5.49 (dd, $J=6.4,2.2 \mathrm{~Hz}, 1 \mathrm{H}), 4.96$ $(\mathrm{dd}, J=6.4,3.2 \mathrm{~Hz}, 1 \mathrm{H}), 4.34(\mathrm{td}, J=6.9,3.2 \mathrm{~Hz}, 1 \mathrm{H}), 4.12(\mathrm{q}, J=7.1 \mathrm{~Hz}, 2 \mathrm{H}), 2.81$ (dd, $J=$ $13.5,6.9 \mathrm{~Hz}, 1 \mathrm{H}), 2.77-2.62(\mathrm{~m}, 5 \mathrm{H}), 2.58-2.50(\mathrm{~m}, 2 \mathrm{H}), 2.34-2.20(\mathrm{~m}, \mathrm{f} 2 \mathrm{H}), 1.73(\mathrm{p}, J=$ $7.3 \mathrm{~Hz}, 2 \mathrm{H}), 1.61(\mathrm{~s}, 3 \mathrm{H}), 1.39(\mathrm{~s}, 3 \mathrm{H}), 1.25(\mathrm{t}, J=7.1 \mathrm{~Hz}, 3 \mathrm{H}) .{ }^{13} \mathrm{C} \mathrm{NMR}\left(100 \mathrm{MHz}, \mathrm{CDCl}_{3}\right)$ $\delta 173.7,155.7,153.2,149.4,140.4,140.3,128.8,128.5,126.1,120.5,114.4,91.2,85.9,83.8$, 83.4, 60.4, 56.4, 56.0, 53.7, 33.4, 31.9, 27.3, 25.5, 22.5, 14.4. HRMS (ESI/TOF-Q) m/z: [M + $\mathrm{H}]^{+}$calcd for C27H37N6O5, 525.2820; found, 525.2841.

4-((((2R,3S,4R,5R)-5-(6-Amino-9H-purin-9-yl)-3,4-dihydroxytetrahydrofuran-2yl)methyl)(phenethyl)amino)butanoic acid $\mathbf{4 b}$

To a solution of acetonide $\mathbf{1 8}(88 \mathrm{mg}, 0.17 \mathrm{mmol})$ in THF $(2 \mathrm{ml})$ and water $(1 \mathrm{ml})$ mixture was added $\mathrm{LiOH}$ (12 $\mathrm{mg}, 0.50 \mathrm{mmol})$ cooling in the ice bath. The reaction mixture was stirred at room temperature for $6 \mathrm{~h}$. The reaction mixture was evaporated under reduced pressure, the residue was dissolved in water $(1 \mathrm{ml})$, cooled in the ice bath, and acidified to $\mathrm{pH} 3$ by addition of $1 \mathrm{~N} \mathrm{HCl}$. The reaction mixture was concentrated to dryness. The residue was dissolved in ice-cold $\mathrm{HCOOH}$ solution in water $(50 \%, 1.5 \mathrm{ml})$. The reaction mixture was stirred at room temperature for 3 days. The solvent was evaporated, then the residue was co-evaporated with $\mathrm{EtOH}$ to remove $\mathrm{HCOOH}$. The residue was chromatographed on $\mathrm{C} 18$ silica on Biotage, eluent acetonitrile in $0.1 \% \mathrm{HCOOH}$, gradient $0-30 \%$ to give $63 \mathrm{mg}(74 \%)$ of the product $4 \mathbf{b}$ as a white foam, which contains 1 equivalent of $\mathrm{HCOOH}$. HPLC purity $92 \%$. ${ }^{1} \mathrm{H}$ NMR $(400 \mathrm{MHz}$, DMSO- $\left.d_{6}\right) \delta 8.36(\mathrm{~s}, 1 \mathrm{H}), 8.15(\mathrm{~s}, 1 \mathrm{H}), 8.14(\mathrm{~s}, 1 \mathrm{H}, \underline{\mathrm{HCOOH}}), 7.27$ (br s, 2H), $7.22-7.16(\mathrm{~m}$, 2H), $7.15-7.10(\mathrm{~m}, 1 \mathrm{H}), 7.09-7.05(\mathrm{~m}, 2 \mathrm{H}), 5.88(\mathrm{~d}, J=5.4 \mathrm{~Hz}, 1 \mathrm{H}), 5.45$ (br s, 1H), 5.18 (br s, 1H), $4.70(\mathrm{t}, J=5.1 \mathrm{~Hz}, 1 \mathrm{H}), 4.12(\mathrm{t}, J=4.8 \mathrm{~Hz}, 1 \mathrm{H}), 4.03-3.97(\mathrm{~m}, 1 \mathrm{H}), 2.89$ (dd, $J=$ 13.9, $4.7 \mathrm{~Hz}, 1 \mathrm{H}), 2.76(\mathrm{dd}, J=13.9,6.9 \mathrm{~Hz}, 1 \mathrm{H}), 2.72-2.60(\mathrm{~m}, 4 \mathrm{H}), 2.52-2.50(\mathrm{~m}, 2 \mathrm{H}$ overlapped with DMSO), $2.18(\mathrm{td}, J=7.2,1.6 \mathrm{~Hz}, 2 \mathrm{H}), 1.62(\mathrm{p}, J=7.2 \mathrm{~Hz}, 2 \mathrm{H}) .{ }^{13} \mathrm{C}$ NMR $\left(100 \mathrm{MHz}, \mathrm{DMSO}-d_{6}\right) \delta 174.6,163.4(\mathrm{HCOOH}), 156.1,152.7,149.5,140.3,140.0,128.6$, $128.2,125.8,119.3,87.8,82.7,72.5,72.0,55.9,55.7,53.2,32.2,31.5,22.1$. HRMS (ESI/TOFQ) $\mathrm{m} / \mathrm{z}:[\mathrm{M}+\mathrm{H}]^{+}$calcd for $\mathrm{C} 22 \mathrm{H} 29 \mathrm{~N} 6 \mathrm{O} 5,457.2194$; found, 457.2206.

\subsection{Synthesis of SAM analogue 4a}

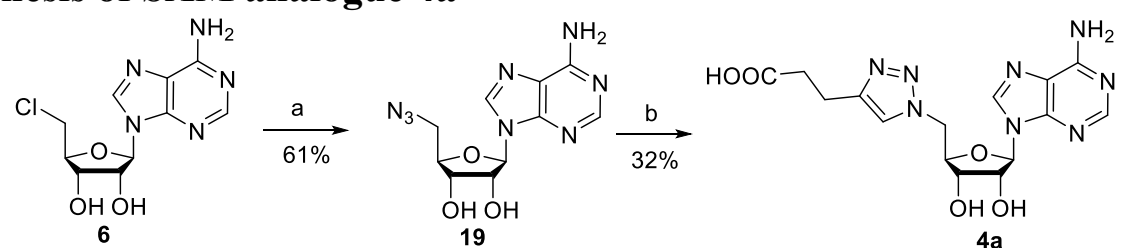

Reagents and conditions: (a) $\mathrm{NaN}_{3}, \mathrm{DMF}, 100^{\circ} \mathrm{C}$; (b) 4-pentynoic acid, $\mathrm{CuBr}$, TBTA, Na ascorbate, $\mathrm{MeOH}$, $\mathrm{MeCN}$, water, rt.

5'-Azido-5'-deoxyadenosine 19

To a solution of $5^{\prime}$-chloro-5'-deoxyadenosine $6(0.40 \mathrm{~g}, 1.4 \mathrm{mmol})$ in dry DMF $(2 \mathrm{ml})$ was added sodium azide $(0.12 \mathrm{~g}, 1.8 \mathrm{mmol})$ and the mixture heated to $100^{\circ} \mathrm{C}$ under argon for $18 \mathrm{~h}$. The solvent was evaporated under reduced pressure. The residue was purified by chromatography on silica gel on Biotage, eluent EtOAc-THF-EtOH-water (200:20:15:0 to 
180:30:25:5). The product was washed with $\mathrm{Et}_{2} \mathrm{O}$ to give $0.25 \mathrm{~g}(61 \%)$ of the product 19 as a yellow solid. ${ }^{1} \mathrm{H}$ NMR $\left(300 \mathrm{MHz}, \mathrm{DMSO}-d_{6}\right) \delta 8.35(\mathrm{~s}, 1 \mathrm{H}), 8.16(\mathrm{~s}, 1 \mathrm{H}), 7.28(\mathrm{~s}, 2 \mathrm{H}), 5.92$ $(\mathrm{d}, J=5.5 \mathrm{~Hz}, 1 \mathrm{H}), 5.57(\mathrm{~d}, J=5.98 \mathrm{~Hz}, 1 \mathrm{H}), 5.38(\mathrm{~d}, J=5.2 \mathrm{~Hz}, 1 \mathrm{H}), 4.75(\mathrm{q}, J=5.5 \mathrm{~Hz}$, $1 \mathrm{H}), 4.19(\mathrm{q}, J=5.0 \mathrm{~Hz}, 1 \mathrm{H}), 4.07-4.01(\mathrm{~m}, 1 \mathrm{H}), 3.68(\mathrm{dd}, J=13.1,7.1 \mathrm{~Hz}, 1 \mathrm{H}), 3.54(\mathrm{dd}, J=$ $13.1,3.9 \mathrm{~Hz}, 1 \mathrm{H})$. Data are consistent with literature values. ${ }^{5}$

3-(1-(((2R,3S,4R,5R)-5-(6-Amino-9H-purin-9-yl)-3,4-dihydroxytetrahydrofuran-2yl)methyl)-1H-1,2,3-triazol-4-yl)propanoic acid 4a

5'-Azido-5'-deoxyadenosine 19 (0.10 g, $0.34 \mathrm{mmol})$, 4-pentynoic acid (34 $\mathrm{mg}, 0.35 \mathrm{mmol})$, copper (I) bromide $(2.5 \mathrm{mg}, 0.02 \mathrm{mmol})$, sodium ascorbate $(4.7 \mathrm{mg}, 0.02 \mathrm{mmol})$ and TBTA $(5.2 \mathrm{mg}, 0.01 \mathrm{mmol})$ were weighted in a vial, flushed with argon and supplied with degassed mixture of $\mathrm{MeOH}(1 \mathrm{ml})$, acetonitrile $(0.5 \mathrm{ml})$, and water $(0.5 \mathrm{ml})$. The vial was sealed and sonicated for $5 \mathrm{~min}$ to dissolve solids, then stirred at room temperature for $18 \mathrm{~h}$. Additional 4pentinoic acid (20 mg, $0.20 \mathrm{mmol})$, sodium ascorbate $(4.0 \mathrm{mg}, 0.020 \mathrm{mmol})$ and copper (I) bromide $(2.4 \mathrm{mg}, 0.017 \mathrm{mmol})$ were added, vial was sealed under argon. The reaction mixture was sonicated for $10 \mathrm{~min}$, and then stirred at room temperature for $3 \mathrm{~h}$. The reaction mixture was concentrated and the residue was chromatographed on C18 silica on Biotage, eluent acetonitrile in water, gradient $3-20 \%$. The product was washed with EtOH:water mixture $(1: 1$, $5 \mathrm{ml}$ ) with several drops of THF ( $5 \mathrm{ml}$ ), filtered, and dried in vacuo to give $43 \mathrm{mg}$ (32\%) of the product 4a as a white solid. HPLC purity $90 \%$. ${ }^{1} \mathrm{H}$ NMR (400 MHz, DMSO- $\left.d_{6}\right) \delta 12.12$ (br s, $1 \mathrm{H}), 8.22(\mathrm{~s}, 1 \mathrm{H}), 8.15(\mathrm{~s}, 1 \mathrm{H}), 7.72(\mathrm{~s}, 1 \mathrm{H}), 7.30(\mathrm{br} \mathrm{s}, 2 \mathrm{H}), 5.90(\mathrm{~d}, J=5.3 \mathrm{~Hz}, 1 \mathrm{H}), 5.58(\mathrm{~d}$, $J=5.8 \mathrm{~Hz}, 1 \mathrm{H}), 5.45(\mathrm{~d}, J=4.7 \mathrm{~Hz}, 1 \mathrm{H}), 4.72(\mathrm{dd}, J=14.1,4.2 \mathrm{~Hz}, 1 \mathrm{H}), 4.76(\mathrm{dd}, J=14.1$, $6.6 \mathrm{~Hz}, 1 \mathrm{H}), 4.65-4.58(\mathrm{~m}, 1 \mathrm{H}), 4.26-4.20(\mathrm{~m}, 2 \mathrm{H}), 2.78(\mathrm{t}, J=7.5 \mathrm{~Hz}, 2 \mathrm{H}), 2.56-2.50(\mathrm{t}$, $2 \mathrm{H}$, overlapped with DMSO). ${ }^{13} \mathrm{C}$ NMR $\left(100 \mathrm{MHz}\right.$, DMSO- $\left.d_{6}\right) \delta 173.7,156.2,152.8,149.3$, 145.8, 140.0, 122.8, 119.36, 87.8, 82.5, 72.7, 71.0, 51.3, 33.1, 20.6. HRMS (ESI/TOF-Q) m/z: $[\mathrm{M}+\mathrm{H}]^{+}$calcd for C15H19N8O5, 391.1473; found, 391.1486.

\subsection{Synthesis of SAM analogue 4c}

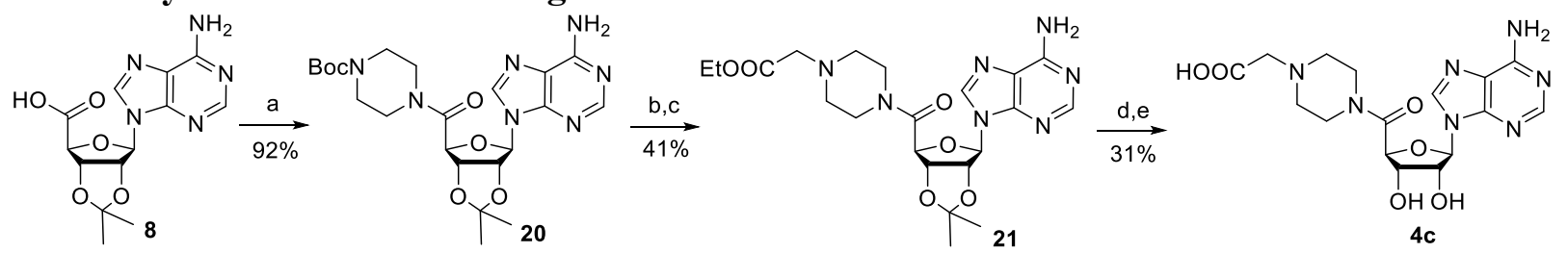

Reagents and conditions: (a) Boc-piperidine, HATU, DIPEA, MeCN, rt; (b) $4 \mathrm{~N} \mathrm{HCl}$ in dioxane, DCM, rt; (c) ethyl bromoacetate, $\mathrm{K}_{2} \mathrm{CO}_{3}$, DMF, $50^{\circ} \mathrm{C}$; (d) $\mathrm{LiOH}$, water, rt. (e) $\mathrm{HCOOH}$, water, rt.

tert-Butyl 4-((3aS,4S,6R,6aR)-6-(6-amino-9H-purin-9-yl)-2,2-dimethyltetrahydrofuro[3,4d] [1,3]dioxole-4-carbonyl)piperazine-1-carboxylate $\mathbf{2 0}$

To a suspension of carboxylic acid $8(0.10 \mathrm{~g}, 0.31 \mathrm{mmol})$, HATU $(0.13 \mathrm{~g}, 0.34 \mathrm{mmol})$ and 1Boc-piperazine $(75 \mathrm{mg}, 0.40 \mathrm{mmol})$ in acetonitrile $(5 \mathrm{ml})$ under argon atmosphere was added DIPEA ( $70 \mu \mathrm{l}, 0.40 \mathrm{mmol})$ dropwise. The reaction mixture was stirred at room temperature for $2 \mathrm{~h}$. The reaction mixture was concentrated and the residue was chromatographed on silica gel on Biotage, eluent EtOAc:EtOH 3:1 in petroleum ether 50-100\% to give $0.14 \mathrm{~g}(92 \%)$ of the product 20 as a white solid. ${ }^{1} \mathrm{H}$ NMR $\left(300 \mathrm{MHz}, \mathrm{DMSO}-d_{6}\right) \delta 8.13(\mathrm{~s}, 1 \mathrm{H}), 8.10(\mathrm{~s}, 1 \mathrm{H}), 7.28$ (br s, 2H), $6.24(\mathrm{~s}, 1 \mathrm{H}), 5.57(\mathrm{~s}, 2 \mathrm{H}), 5.09(\mathrm{~s}, 1 \mathrm{H}), 3.54-3.33(\mathrm{~m}, 5 \mathrm{H}$, overlapped with water), $3.11-3.00(\mathrm{~m}, 1 \mathrm{H}), 2.83-2.67(\mathrm{~m}, 1 \mathrm{H}), 2.63-2.52(\mathrm{~m}, 1 \mathrm{H}), 1.54(\mathrm{~s}, 3 \mathrm{H}), 1.37(\mathrm{~s}, 12 \mathrm{H}) .{ }^{13} \mathrm{C}$ NMR $\left(100 \mathrm{MHz}, \mathrm{DMSO}-d_{6}\right) \delta 166.8,156.0,153.7,152.7,149.4,139.3,118.5,112.7,88.8$, 83.3, 83.0, 82.1, 79.2, 44.8, 41.3, 28.0, 26.5, 24.9. HRMS (ESI/TOF-Q) m/z: $[\mathrm{M}+\mathrm{H}]^{+}$calcd for C22H31N7O6, 490.2409; found, 490.2423. 
Ethyl 2-(4-((3aS $\quad 4 S, 6 R, 6 \mathrm{a} R)-6$-(6-amino-9H-purin-9-yl)-2,2-dimethyltetrahydrofuro[3,4d] [1,3]dioxole-4-carbonyl)piperazin-1-yl)acetate 21

To a suspension of Boc-piperazine derivative 20 ( $0.13 \mathrm{~g}, 0.27 \mathrm{mmol})$ in DCM ( $3 \mathrm{ml})$ was added $4 \mathrm{~N} \mathrm{HCl}$ in dioxane $(0.26 \mathrm{ml}, 1.0 \mathrm{mmol})$ and the reaction mixture was stirred at room temperature for $16 \mathrm{~h}$. The solvent was evaporated, then the residue was co-evaporated with $\mathrm{DCM}$ to remove $\mathrm{HCl}$. The residue was dissolved in DMF $(1 \mathrm{ml})$, then potassium carbonate (66 $\mathrm{mg}, 0.48 \mathrm{mmol})$ was added, followed by ethyl bromoacetate $(29 \mu \mathrm{l}, 0.26 \mathrm{mmol})$. The reaction mixture was stirred at room temperature for $1 \mathrm{~h}$, then at $50^{\circ} \mathrm{C}$ for $19 \mathrm{~h}$. The reaction mixture was concentrated. The residue was chromatographed on silica gel on Biotage, eluent EtOAc:EtOH 3:1 in petroleum ether 50-100\% to give $47 \mathrm{mg}(41 \%)$ of the product 21 as a glasslike solid. ${ }^{1} \mathrm{H}$ NMR $\left(400 \mathrm{MHz}, \mathrm{D}_{2} \mathrm{O}\right) \delta 8.19(\mathrm{~s}, 1 \mathrm{H}), 8.04(\mathrm{~s}, 1 \mathrm{H}), 6.27(\mathrm{~s}, 1 \mathrm{H}), 5.76(\mathrm{~d}, J=6.0$ $\mathrm{Hz}, 1 \mathrm{H}), 5.74(\mathrm{~d}, J=6.0 \mathrm{~Hz}, 1 \mathrm{H}), 5.15(\mathrm{~s}, 1 \mathrm{H}), 4.16(\mathrm{q}, J=7.1 \mathrm{~Hz}, 1 \mathrm{H}), 3.71-3.60(\mathrm{~m}, 1 \mathrm{H})$, $3.57-3.46(\mathrm{~m}, 1 \mathrm{H}), 3.25-3.15(\mathrm{~m}, 1 \mathrm{H}), 2.94-2.81(\mathrm{~m}, 1 \mathrm{H}), 2.88(\mathrm{~s}, 2 \mathrm{H}), 2.65-2.52(\mathrm{~m}$, $1 \mathrm{H}), 1.64(\mathrm{~s}, 3 \mathrm{H}), 1.50(\mathrm{~s}, 3 \mathrm{H}), 1.41-1.33(\mathrm{~m}, 1 \mathrm{H}), 1.24(\mathrm{t}, J=7.1 \mathrm{~Hz}, 3 \mathrm{H}), 1.22-1.11(\mathrm{~m}$, 1H). ${ }^{13} \mathrm{C}$ NMR $\left(100 \mathrm{MHz}, \mathrm{D}_{2} \mathrm{O}\right) \delta 171.1,167.6,155.5,152.8,149.0,140.2,118.3,114.0,89.3$, 83.3, 82.7, 82.2, 61.9, 58.2, 51.8, 51.5, 44.7, 41.3, 25.4, 23.9, 13.3. HRMS (ESI/TOF-Q) m/z: $[\mathrm{M}+\mathrm{H}]^{+}$calcd for C21H30N7O6, 476.2252; found, 476.2257.

2-(4-((2S,3S,4R,5R)-5-(6-Amino-9H-purin-9-yl)-3,4-dihydroxytetrahydrofuran-2carbonyl)piperazin-1-yl)acetic acid $\mathbf{4 c}$

Ethyl 2-(4-((3aS,4S,6R,6aR)-6-(6-amino-9H-purin-9-yl)-2,2-dimethyltetrahydrofuro[3,4d][1,3]dioxole-4-carbonyl)piperazin-1-yl)acetate $21(0.14 \mathrm{~g}, 0.29 \mathrm{mmol})$ was vigorously stirred with $\mathrm{LiOH}(21 \mathrm{mg}, 0.88 \mathrm{mmol})$ in water $(1 \mathrm{ml})$ at room temperature for $1 \mathrm{~h}$. The reaction mixture was supplemented with $1 \mathrm{~N} \mathrm{HCl}(0.8 \mathrm{ml}, 0.80 \mathrm{mmol})$ and the solvent was evaporated. The residue was dissolved in ice-cold $\mathrm{HCOOH}$ solution in water $(50 \%, 2 \mathrm{ml})$. The reaction mixture was stirred at $50^{\circ} \mathrm{C}$ for $24 \mathrm{~h}$. The solvent was evaporated, then the residue was co-evaporated with $\mathrm{EtOH}$ to remove $\mathrm{HCOOH}$. The residue was chromatographed on $\mathrm{C} 18$ silica on Biotage, eluent acetonitrile in $0.1 \% \mathrm{HCOOH}$, gradient $3-20 \%$, then freezedried to give $41 \mathrm{mg}(31 \%)$ of the product $\mathbf{4 c}$ as a white solid, which contains 1 equivalent $\mathrm{HCOOH}(\mathrm{NMR})$. HPLC purity 97\%. ${ }^{1} \mathrm{H}$ NMR (400 MHz, $\left.\mathrm{D}_{2} \mathrm{O}\right) \delta 8.53(\mathrm{~s}, 1 \mathrm{H}), 8.35(\mathrm{~s}, 1 \mathrm{H}$, $\underline{\mathrm{HCOOH}}), 8.25(\mathrm{~s}, 1 \mathrm{H}), 6.20(\mathrm{~d}, J=5.4 \mathrm{~Hz}, 1 \mathrm{H}), 5.14(\mathrm{~d}, J=3.7 \mathrm{~Hz}, 1 \mathrm{H}), 4.79-4.76(\mathrm{~m}$, $1 \mathrm{H}$, overlapped with water), $4.69-4.64(\mathrm{~m}, 1 \mathrm{H}), 4.12-3.85(\mathrm{~m}, 4 \mathrm{H}), 3.77(\mathrm{~s}, 2 \mathrm{H}), 3.57-$ $3.32(\mathrm{~m}, 4 \mathrm{H}) .{ }^{13} \mathrm{C}$ NMR $\left(100 \mathrm{MHz}, \mathrm{D}_{2} \mathrm{O}\right) \delta 169.3,168.9(\mathrm{HCOOH}), 168.3,152.9,149.1$, 148.6, 141.2, 118.5, 88.0, 80.5, 73.9, 72.5, 58.2, 51.8, 51.7, 42.2, 39.1. HRMS (ESI/TOF-Q) $\mathrm{m} / \mathrm{z}:[\mathrm{M}+\mathrm{H}]^{+}$calcd for $\mathrm{C} 16 \mathrm{H} 22 \mathrm{~N} 7 \mathrm{O} 6,408.1626$; found, 408.1635 .

\section{Molecular modelling}

Inhibitors bearing bioisosteric substituents of the sulfonium and amino acid groups were designed either by experienced medicinal chemists or using standard protocol implemented in Isosteric Matching tool in Maestro software ${ }^{6}$ and then docked in the crystal structure of SARSCoV-1 Nsp14 (PDB ID: 5C8T), SARS-CoV-2 Nsp16 (PDB ID: 6W4H) and human RNA (guanine-N7-) MTase (PDB ID: 3BGV). Protein crystal structures were prepared using Maestro Protein Preparation Wizard ${ }^{6}$ by adding missing side chains using Prime, ${ }^{7}$ adjusting side chain protonation states at $\mathrm{pH} 7$, and minimizing heavy atoms with convergence up to 0.30 A. ${ }^{8}$ Inhibitors were prepared for docking using standard protocol implemented in LigPrep at $\mathrm{pH}$ 7. SAM analogue docking was performed by restraining the adenosyl group of the inhibitor to the reference ligand (SAM or SAH) adenosyl group pose with tolerance up to $0.1 \AA$. Scaling of the van der Waals radii was set to 0.9 for protein and ligand heavy atoms. Molecular docking was performed using Glide ${ }^{9}$ with standard precision (Glide SP) and docked poses were 
visualized using PyMOL. ${ }^{10}$ Compounds were prioritized based on docking scores against Nsp14 and Nsp16, and the docking score against the human MTase was not considered for compound selection, because the difference in the compound docking scores between the different MTases was at the level of scoring uncertainty $(\sim 2 \mathrm{kcal} / \mathrm{mol})$.

\section{Protein expression and purification}

Nsp14 gene sequence were purchased as a gene synthesis from General Biosystems with codon optimization for $E$. coli expression system in pET28a vector. NdeI and NotI restriction sites were used for this construct, and the construct contained an additional N-terminal His-6x tag with thrombin cleavage site. Nsp10 and Nsp16 were ordered from ATCC repository as NR-52425 and NR-52427 catalog items, respectively. Nsp10 and Nsp16 constructs were cloned in pMCSG53 vector and contained additional N-terminal His-6x tag with tobacco etch virus protease cleavage sites.

Protein expression was performed in E. coli BL21-DE3 cells. Cells were maintained in LB medium supplemented with $30 \mu \mathrm{g} / \mathrm{ml}$ kanamycin, and the protein expression was performed in 2 XTY medium supplemented with $30 \mu \mathrm{g} / \mathrm{ml}$ kanamycin. Cells were grown at $+37^{\circ} \mathrm{C}$ to $\mathrm{OD}_{590} 0.7$ and shaken at $200 \mathrm{rpm}$, cooled at $20^{\circ} \mathrm{C}$ for $30 \mathrm{~min}$ and induced with $1 \mathrm{mM}$ IPTG. Induction was performed overnight for approximately $16 \mathrm{~h}$ at $20^{\circ} \mathrm{C}$ with shaking at $200 \mathrm{rpm}$. Biomass was collected by centrifugation and stored at $-20^{\circ} \mathrm{C}$.

Procedures for Nsp10, Nsp14 and Nsp16 purification were identical. Note that reducing conditions during purification procedures are extremely important for stability of Nsp16 and Nsp14. The purification protocol was adopted from previous study ${ }^{11}$ with modifications. Cell disruption was performed with ultrasonication in $50 \mathrm{mM}$ Tris- $\mathrm{HCl}(\mathrm{pH} 9.0), 500 \mathrm{mM} \mathrm{NaCl}$, $10 \mathrm{mM}$ 2-mercaptoethanol, $2 \mathrm{mM} \mathrm{MgCl} 2,0.1 \%$ (v/v) Triton X-100, 10\% (v/v) glycerol and $50 \mathrm{mM}$ imidazole. Then the lysate was centrifuged for $30 \mathrm{~min}$ at $11000 \mathrm{x} \mathrm{g}$. The proteins were purified from lysate with IMAC using either batch or column $\mathrm{Ni}^{2+}$-NTA agarose. The $\mathrm{Ni}^{2+}$-NTA agarose were previously equilibrated in $50 \mathrm{mM}$ Tris- $\mathrm{HCl}(\mathrm{pH} 9.0), 0.5 \mathrm{M} \mathrm{NaCl}, 10$ $\mathrm{mM}$ 2-mercaptoethanol, $2 \mathrm{mM} \mathrm{MgCl}, 5 \%(\mathrm{v} / \mathrm{v})$ glycerol and $50 \mathrm{mM}$ imidazole and then were washed with the same buffer. Proteins were eluted with a buffer containing $50 \mathrm{mM}$ Tris$\mathrm{HCl}$ (pH 9.0), $0.5 \mathrm{M} \mathrm{NaCl}, 10 \mathrm{mM}$ 2-mercaptoethanol, $2 \mathrm{mM} \mathrm{MgCl}_{2}, 5 \%(\mathrm{v} / \mathrm{v})$ glycerol and 1 $\mathrm{M}$ imidazole.

Nsp10 and Nsp16 for Nsp16/Nsp10 assay were cleaved overnight with TEV protease by adding it to the protein solution at a ratio of $1 \mathrm{mg}$ per $30 \mathrm{mg}$ of cleavable protein.

The proteins were then further purified with size exclusion chromatography on a Superdex 200 column in $20 \mathrm{mM}$ HEPES ( $\mathrm{pH} 8.5$ ), $0.5 \mathrm{M} \mathrm{NaCl}, 10 \mathrm{mM}$ 2-mercaptoethanol, $2 \mathrm{mM}$ $\mathrm{MgCl}_{2}$ and $5 \%(\mathrm{v} / \mathrm{v})$ glycerol. The peak fractions were then pooled. In the case of Nsp16/Nsp10 a separation of uncleaved protein and TEV protease was performed at this point by passing this material through $\mathrm{Ni}^{2+}$-NTA agarose column.

Nsp16 and Nsp10 were mixed in equimolar ratios and concentrated with ultrafiltration to a concentration of $2 \mathrm{mg} / \mathrm{ml}$. SAM was added to a concentration of $2 \mathrm{mM}$ and the mixture was incubated overnight at $+4{ }^{\circ} \mathrm{C}$ to allow proper complex formation. In the next day the mixture was dialyzed against $20 \mathrm{mM}$ HEPES (pH 7.5), $0.15 \mathrm{M} \mathrm{NaCl}, 5 \%$ glycerol and $1 \mathrm{mM}$ TCEP for 2 hours to remove excess SAM, and then concentrated to $5 \mathrm{mg} / \mathrm{ml}$ with ultrafiltration. The solution was then flash-frozen in liquid nitrogen and stored at $-20{ }^{\circ} \mathrm{C}$. 


\section{Enzymatic assays}

\subsection{Homogeneous time-resolved fluorescent energy transfer (HTRF) assay}

MTase activity was determined with an EPIgeneous Methyltransferase Assay kit by assaying the conversion of SAM to SAH according to the manufacturer's instructions.

The enzymatic reaction was performed in white ProxiPlate-384 Plus microplates using a final reaction volume of $10 \mu \mathrm{l}$. The reaction buffer was composed of $40 \mathrm{mM}$ Tris-HCl $\mathrm{pH} 8.3(\mathrm{pH}$ 8.0 for $\mathrm{Nsp} 16 / \mathrm{Nsp} 10$ ) and $100 \mathrm{mM} \mathrm{NaCl}$ (or $10 \mathrm{mM} \mathrm{KCl}$ only for Nsp16/Nsp10), $1 \mathrm{mM}$ DTT, $2 \mathrm{mM} \mathrm{MgCl} 2,0.01 \%$ Tween20. $4 \mu$ of purified recombinant protein Nsp14 at $0.4 \mu \mathrm{M}$ or Nsp16/Nsp10 at $3 \mu \mathrm{M}$ final concentration were added in the assay wells, containing previously dispensed inhibitors. The reaction was started by preparing a mix containing $4 \mu \mathrm{M}$ GpppG (Jena Bioscience, cat.nr. NU854) or $\sim 5 \mu \mathrm{M}$ m7GpppA-RNA (for Nsp16/Nsp10) and SAM at $10 \mu \mathrm{M}$ final concentrations in a volume of $4 \mu \mathrm{l}$, which was incubated at $37^{\circ} \mathrm{C}$ for 20 $\min (2 \mathrm{~h}$ for Nsp16/Nsp10).

All compounds were dissolved in $100 \%$ DMSO ( $0.1 \%$ final DMSO concentration) and were tested at $100 \mu \mathrm{M}$ concentration in duplicate. $\mathrm{IC}_{50}$ values were determined for compounds showing higher than $50 \%$ inhibitory effect at $100 \mu \mathrm{M}$ concentration.

For the detection of released SAH, $2 \mu \mathrm{l}$ of EPIgeneous detection buffer one was added in order to stop the enzymatic reaction. After $10 \mathrm{~min}$ of incubation at room temperature, detection reagents were added: first, $4 \mu \mathrm{l}$ of a 1/16 dilution of SAH-d2 conjugate and then 4 $\mu \mathrm{l}$ of Anti-SAH-Lumi4-Tb at a 1/100 dilution. HTRF signals were measured using a Hidex Sense (Finland) microplate reader using an excitation filter at $337 \mathrm{~nm}$ and fluorescence wavelength measurements at 620 and $665 \mathrm{~nm}$, an integration delay of $150 \mathrm{~ms}$, and an integration time of $400 \mathrm{~ms}$. Results were analysed by calculating a two-wavelength signal ratio: [intensity $(665 \mathrm{~nm})$ /intensity $(620 \mathrm{~nm}){ }^{*} 10^{4}$ (HTRF Ratio). The mean HTRF Ratio for each sample was calculated as:

Mean HTRF Ratio = Mean Sample HTRF Ratio - Blank HTRF Ratio, where 'blank' is the signal with compound (or DMSO in control sample) and Anti-SAH-Lumi4-Tb.

Percent inhibition was calculated using the following formula for each inhibitor dilution: $\%$ Inhibition $=100-\left(\right.$ max signal $_{\text {comp }}-$ min signal comp $) * 100 /($ max signal control - min signal control), where 'max signal' is the signal ratio without protein (negative control) and 'min signal' the signal ratio in sample. The $\mathrm{IC}_{50}$ value was calculated using the program Graph Pad Prism ${ }^{\circledR} 8.0$.

The selectivity of the compounds was tested using human Glycine N-Methyltransferase (GNMT from MyBioSource, cat. nr. MBS636160) using the same EPIgeneous Methyltransferase Assay kit. Reaction mixtures (volume $10 \mu \mathrm{l}$ ) contained $20 \mathrm{mM}$ Tris- $\mathrm{HCl}$ (pH 8.6), $2 \mathrm{mM} \mathrm{MgCl}, 0.5 \mu \mathrm{M}$ GNMT, and compounds $1 \mathrm{nM}-10 \mu \mathrm{M}$. The reaction was started with a mix containing glycine and SAM at $5 \mathrm{mM}$ and $10 \mu \mathrm{M}$ final concentrations respectively and incubated at $25^{\circ} \mathrm{C}$ for $30 \mathrm{~min}$. Released $\mathrm{SAH}$ was detected and compound $\mathrm{IC}_{50}$ values were determined as described above.

\subsection{SARS-CoV-2 Nsp16/Nsp10 methyltransferase substrate RNA production}

RNA oligonucleotide substrate for the Nsp16/Nsp10 assay was acquired through in vitro transcription with Thermo Fisher TranscriptAid T7 High Yield Transcription Kit, using a DNA oligonucleotide Co25F 5'-TAC AAA GCT TCA GTA ATA CGA CTC ACT ATT ATA GAA CTT CGT CGA GTA CGC TCA A as a sense strand, and a DNA oligonucleotide 
Co25R 5'-TTG AGC GTA CTC GAC GAA GTT CTA TAA TAG TGA GTC GTA TTA CTG AAG CTT TGT A as a complimentary strand, to allow the transcription from the class II T7 promoter 5'- TAATACGACTCACTATTA 3' and to obtain the RNA oligonucleotide m7G(5')ppp(5')Co25: m7G(5')ppp(5')AUAGAACUUCGUCGAGUACGCUCAA.

In vitro transcription reaction was set up as follows:

\begin{tabular}{|l|l|}
\hline DEPC-treated water & $6 \mu \mathrm{l}$ \\
\hline 5x TranscriptAid reaction buffer & $4 \mu \mathrm{l}$ \\
\hline ATP, Tris buffered, $30 \mathrm{mM}$ & $1 \mu \mathrm{l}(1.5 \mathrm{mM}$ final concentration $)$ \\
\hline CTP, Tris buffered, $100 \mathrm{mM}$ & $1.5 \mu \mathrm{l}(7.5 \mathrm{mM}$ final concentration $)$ \\
\hline GTP, Tris buffered, $100 \mathrm{mM}$ & $1.5 \mu \mathrm{l}(7.5 \mathrm{mM}$ final concentration $)$ \\
\hline UTP, Tris buffered, $100 \mathrm{mM}$ & $1.5 \mu \mathrm{l}(7.5 \mathrm{mM}$ final concentration $)$ \\
\hline Cap analog G( $\left.5^{\prime}\right) \mathrm{ppp}\left(5^{\prime}\right) \mathrm{A}, 100 \mathrm{mM}$ & $1.2 \mu \mathrm{L}(6 \mathrm{mM}$ final concentration $)$ \\
\hline $\begin{array}{l}\text { Co25 template DNA, double stranded, } \\
\text { preheated at } 95{ }^{\circ} \mathrm{C} \text { for } 10 \mathrm{~min}, \text { then slowly } \\
\text { cooled down to } 35^{\circ} \mathrm{C}\end{array}$ & $1 \mathrm{ug}(0.5 \mu \mathrm{l})$ \\
\hline TranscriptAid enzyme mix $^{\text {The }}$ & $2 \mu \mathrm{l}$ \\
\hline
\end{tabular}

The reaction was incubated for 6 hours at $37^{\circ} \mathrm{C}$, products were desalted via Thermo Scientific Zeba Spin Desalting Columns, 7K MWCO, $0.5 \mathrm{ml}$ in DEPC-treated water, then stored at $-20{ }^{\circ} \mathrm{C}$.

A co-transcriptionally capped $\mathrm{m} 7 \mathrm{G}\left(5^{\prime}\right) \mathrm{ppp}\left(5^{\prime}\right)$-Co25 oligonucleotide was obtained using 1.5 $\mathrm{mM}$ final concentration of ATP and $6.0 \mathrm{mM}$ final concentration of G(5')ppp(5')A RNA Cap Structure Analog obtained from New England Bio Labs inc. Oligonucleotide was purified from template DNA by digestion with DNAse I for $15 \mathrm{~min}$ at $37^{\circ} \mathrm{C}$ and subsequent desalting via Thermo Scientific Zeba Spin Desalting Columns, 7K MWCO, $0.5 \mathrm{ml}$ in DEPC-treated water.

RNA oligonucleotide concentration was measured using Nanodrop 2000 spectrophotometer, yielding concentrations of $2.5 \pm 0.5 \mu \mathrm{g} / \mu \mathrm{l}$ and the oligonucleotides were analyzed by $20 \%$ polyacrylamide denaturing ( $7 \mathrm{M}$ urea) gel electrophoresis, where they appeared as a diffuse band around $8.3-8.6 \mathrm{kDa}$ (Figure $\mathrm{S} 1$ ).

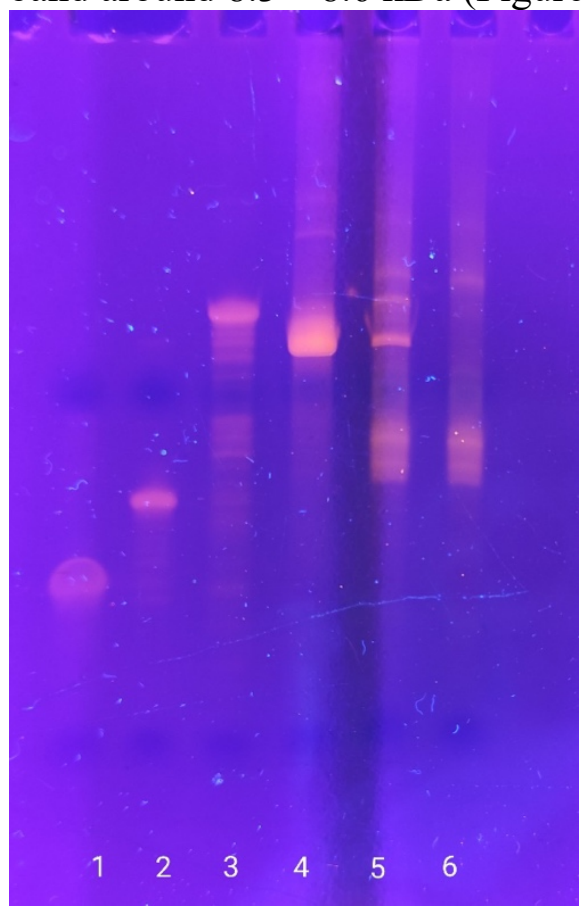

Figure S1. Analysis of RNA transcripts by $20 \%$ polyacrylamide denaturing gel electrophoresis.

1. $-5.8 \mathrm{kDa}$ standard

2. $-8.3 \mathrm{kDa}$

3. $-19.3 \mathrm{kDa}$

4. - DNA template

5. - m7G(5')ppp (5')Co25 co-transcriptionally capped RNA, before DNAse digestion

6. - $\mathrm{m} 7 \mathrm{G}\left(5^{\prime}\right) \operatorname{ppp}\left(5^{\prime}\right) \mathrm{Co} 25$ co-transcriptionally capped RNA, after DNAse digestion, desalted 


\section{Cell lines and culture}

A549 human non-small cell lung cancer cell line, HepG2 hepatocarcinoma cells and BALB/c 3 T3 clone A31 murine fibroblast cell line for the study were obtained from ATCC. Cells were propagated in DMEM medium (Sigma, D6046) supplemented with 1\% penicillin (100 U/mL)streptomycin $(100 \mu \mathrm{g} / \mathrm{mL})$ and 10\% fetal bovine serum (Sigma, F7524) in case of A549 and HepG2 or $10 \%$ calf serum (Sigma, C8056) in case of BALB/c 3T3. All cultivations were performed in a humidified $5 \% \mathrm{CO}_{2}$ atmosphere at $37^{\circ} \mathrm{C}$.

\section{Cytotoxicity testing}

The cytotoxicity of the compounds was tested in A549, HepG2 and BALB/c3T3 cell lines by neutral red (NR) uptake assay. A549 and BALB/c3T3 cells were seeded in 96-well plates at density $8 \times 10^{3}$ cells per well, HepG2 at density $1.2 \times 10^{4}$ cells per well. After $24 \mathrm{~h}$ incubation test compounds in concentration range 0.8 to $200 \mu \mathrm{M}$ were added. Cultivation in presence of test compounds was done for $48 \mathrm{~h}$. Afterwards the plate was washed with phosphate buffered saline (PBS) (Sigma, D8537) and $25 \mu \mathrm{g} / \mathrm{ml}$ NR solution (Sigma, N2889) was added. In case of BALB/c 3T3 cells, NR was diluted in 5\% fetal calf serum containing media, while for A549 and HepG2 cells - in 5\% fetal bovine serum containing media. After $3 \mathrm{~h}$ incubation plate was washed with PBS and NR taken up by viable cells was extracted using desorbing fixative (50\%ethanol/1\%acetic acid/49\% water). Absorbance at $540 \mathrm{~nm}$ was measured using Tecan M200 Infinite Pro microplate reader.

Cytotoxicity was expressed as a concentration-dependent reduction of the uptake of NR, compared to the untreated controls, $\mathrm{IC}_{50}$ value for each compound was calculated.

\section{Cell permeability testing}

\subsection{Compound incubation in cell culture}

To test cell permeability each compound was added to A549 cell culture at concentration 20 $\mu \mathrm{M}$ and incubated for $24 \mathrm{~h}$. Cells were seeded in 6-well plates at density $2 \times 10^{4}$ and $4 \times 10^{4}$ cells per well at concentrations $1 \times 10^{4}$ and $2 \times 10^{4}$ cells $/ \mathrm{ml}$ media for testing of each compound, each in three replicates.

After the incubation cell cultivation media and cell lysates were collected. After removal of media cells were washed with ice-cold PBS (Sigma, D1408) and lysed for 30 minutes in 500 $\mu \mathrm{L}$ per well ice-cold RIPA buffer (Sigma, R0278). Samples were stored at $-80{ }^{\circ} \mathrm{C}$ until analysis.

\subsection{LC/MS/MS analysis}

Quantitative determination of tested compounds in cell lysates and culture media was performed on a Waters MICROMASS QUATTRO micro ${ }^{\mathrm{TM}}$ tandem mass spectrometer combined with Acquity UPLC system. Acquity UPLC BEH C8 (2.1 x $50 \mathrm{~mm}$ x $1.7 \mu \mathrm{m})$ column was used at a flow rate of $0.25 \mathrm{~mL} / \mathrm{min}$. The column oven was set at $30^{\circ} \mathrm{C}$, and the sample injection volume was $5 \mu \mathrm{L}$. The mobile phase consisted of a combination of A $(0.1 \%$ formic acid in water) and B (acetonitrile). Gradient elution program from $5 \%$ B to $98 \% \mathrm{~B}$ in 5 min was applied for analysis. Tandem mass spectrometer in positive electrospray mode was used for quantification. Multiple reaction monitoring (MRM) parameters are detailed in Table S1. The TargetLynx software was applied to process LC/MS/MS data.

Samples for LC/MS/MS analysis were prepared as follows: $200 \mu \mathrm{L}$ of acetonitrile/methanol mixture $(3: 1 . \mathrm{v} / \mathrm{v})$ was add to $200 \mu \mathrm{L}$ of each cell lysate and culture media sample. The samples were then centrifuged $(10,000 \mathrm{rpm}, 10 \mathrm{~min})$ and the supernatant $(300 \mu \mathrm{L})$ were removed from each sample and placed in vials for LC/MS/MS analysis. Calibration curves 
for all analytes were produced by analysis of standard solutions over a concentration range of 0.2 to $20 \mu \mathrm{M}$.

Table S1. MRM parameters.

\begin{tabular}{|c|c|c|c|}
\hline Test compound & MRM transitions & Cone voltage, V & $\begin{array}{c}\text { Collision } \\
\text { energy, eV }\end{array}$ \\
\hline 1a & $404.2>136.1$ & 20 & $20 ; 20$ \\
\hline $\mathbf{1 b}$ & $401.1>136.1 ; 379.2>136.1$ & 20 & $20 ; 20$ \\
\hline $\mathbf{2 a}$ & $418.1>136.1$ & 20 & 20 \\
\hline $\mathbf{2 b}$ & $424.2>136.1 ; 424.2>141.1$ & 20 & $20 ; 20$ \\
\hline $\mathbf{3 a}$ & $379.2>128.0 ; 379.2>136.1$ & 20 & $20 ; 20$ \\
\hline 3b & $380.2>136.1$ & 20 & 15 \\
\hline 4a & $391.1>136.2 ; 391.1>256.1$ & 20 & $25 ; 20$ \\
\hline 4b & $457.2>322.1$ & 20 & 20 \\
\hline
\end{tabular}




\section{References}

(1) Duclos, R. I.; Cleary, D. C.; Catcott, K. C.; Zhou, Z. S. Synthesis and Characterization of Se-Adenosyl-L-Selenohomocysteine Selenoxide. J. Sulphur Chem. 2015, 36 (2), 135-144. https://doi.org/10.1080/17415993.2014.979173.

(2) Dal Ben, D.; Buccioni, M.; Lambertucci, C.; Marucci, G.; Spinaci, A.; Marchenkova, A.; Abdelrahman, A.; Nistri, A.; Müller, C. E.; Volpini, R. Investigation on 2',3'-OSubstituted ATP Derivatives and Analogs as Novel P2X3 Receptor Antagonists. ACS Med. Chem. Lett. 2019, 10 (4), 493-498. https://doi.org/10.1021/acsmedchemlett.8b00524.

(3) Kai, K.; Fujii, H.; Ikenaka, R.; Akagawa, M.; Hayashi, H. An Acyl-SAM Analog as an Affinity Ligand for Identifying Quorum Sensing Signal Synthases. Chem. Commun. 2014, 50 (62), 8586-8589. https://doi.org/10.1039/c4cc03094j.

(4) Zhang, G.; Richardson, S. L.; Mao, Y.; Huang, R. Design, Synthesis, and Kinetic Analysis of Potent Protein N-Terminal Methyltransferase 1 Inhibitors. Org. Biomol. Chem. 2015, 13 (14), 4149-4154. https://doi.org/10.1039/c5ob00120j.

(5) Klima, M.; Baumlova, A.; Chalupska, D.; Hřebabecký, H.; Dejmek, M.; Nencka, R.; Boura, E. The High-Resolution Crystal Structure of Phosphatidylinositol 4-Kinase II $\beta$ and the Crystal Structure of Phosphatidylinositol 4-Kinase II $\alpha$ Containing a Nucleoside Analogue Provide a Structural Basis for Isoform-Specific Inhibitor Design. Acta Crystallogr. D Biol. Crystallogr. 2015, 71 (Pt 7), 1555-1563. https://doi.org/10.1107/S1399004715009505.

(6) Schrödinger Release 2021-1: Maestro; Schrödinger, LLC: New York, NY, 2021.

(7) Schrödinger Release 2021-1: Prime; Schrödinger, LLC: New York, NY, 2021.

(8) Madhavi Sastry, G.; Adzhigirey, M.; Day, T.; Annabhimoju, R.; Sherman, W. Protein and Ligand Preparation: Parameters, Protocols, and Influence on Virtual Screening Enrichments. J Comput Aided Mol Des 2013, 27 (3), 221-234. https://doi.org/10.1007/s10822-013-9644-8.

(9) Schrödinger Release 2021-1: Glide; Schrödinger, LLC: New York, NY, 2021.

(10) The PyMOL Molecular Graphics System; Schrödinger, LLC.

(11) Rosas-Lemus, M.; Minasov, G.; Shuvalova, L.; Inniss, N. L.; Kiryukhina, O.; Wiersum, G.; Kim, Y.; Jedrzejczak, R.; Maltseva, N. I.; Endres, M.; Jaroszewski, L.; Godzik, A.; Joachimiak, A.; Satchell, K. J. F. The Crystal Structure of Nsp10-Nsp16 Heterodimer from SARS-CoV-2 in Complex with S-Adenosylmethionine. bioRxiv 2020. https://doi.org/10.1101/2020.04.17.047498. 